\title{
SOBRE LAS BASES ECONÓMICAS DE LAS ARISTOCRACIAS EN LA GALLAECIA SUEVO-VISIGODA (ca. 530-650 D.C). COMERCIO, MINERÍA Y ARTICULACIÓN FISCAL
}

\author{
ON THE ECONOMICAL BASES OF THE ARISTOCRACIES IN THE \\ SUEVIC-VISIGOTHIC GALLAECIA (ca.530-650 A.D.). \\ TRADE, MINING AND FISCAL ARTICULATION
}

\author{
JoSÉ CARLOS SÁNCHEZ PARDO \\ Institute of Archaeology-University College London
}

\begin{abstract}
Resumen: La combinación de recientes avances en áreas tan diferentes como el comercio a larga distancia, las acuñaciones monetarias y los estudios de paleoambiente, permiten constatar la existencia en el Noroeste peninsular de un interesante sistema productivo destinado a la exportación entre inicios del siglo VI y mitad del siglo VII d.C. Este trabajo pretende profundizar en el conocimiento de este sistema económico, a través principalmente de una de sus piezas más representativas: la minería, y desde este conocimiento, comprender mejor las bases materiales del poder social y político de las élites locales y regionales de Gallaecia suevo-visigoda y sus mecanismos de articulación con el poder monárquico central. La integración de distintos tipos de datos nos permitirá observar una verdadera geografía del poder económico del Noroeste, en la que los obispos y jerarquías eclesiásticas debieron de jugar un papel mucho más dinámico del que las fuentes textuales transmiten.
\end{abstract}

Palabras clave: tardoantigüedad; minería; obispos; Gallaecia; comercio; acuñaciones monetarias; élites locales.

\begin{abstract}
Recent advances in areas of research as different as long-distance trade, coin minting, and paleoenvironmental studies, have led us to confirm the existence in the northwest of the Iberian Peninsula of an interesting system of production intended for export from the early sixth century to the mid-seventh century $\mathrm{AD}$. This paper has two main objectives. The first is to improve our knowledge of this economic system, mainly studying one of its most representative sectors: mining. Second, based on this knowledge we will try to gain a better understanding of the material basis of the social and political power of local and regional elites in the SuevicVisigothic Gallaecia and the mechanisms for articulating their power with royal central power. The integration of different kinds of data allows us to observe a real geography of economic power in northwest Iberia. Specifically, bishops and the main church hierarchies seem to have played a much more dynamic role than the textual sources indicate.
\end{abstract}

Keywords: late Antiquity; mining; bishops; Gallaecia; trade; coin minting; local elites. 


\section{SUMARIO}

1. Introducción.- 2. La constatación de un sistema productivo-comercial supralocal en el Noroeste peninsular tardoantiguo.- 2.1. Comercio marítimo de larga distancia en la Gallaecia tardoantigua.- 2.2. Actividades minero-metalúrgicas en el Noroeste tardoantiguo. - 3. Evidencias y características de la minería en la Gallaecia tardoantigua.- 3.1. El contexto geográfico-arqueológico de la minería tardoantigua en el Noroeste peninsular.- 3.2. Explotación y distribución de la producción metalífera.4. Poder y articulación económica en la Gallaecia tardoantigua. - 4.1. La monarquía suevo-visigoda y la minería en Gallaecia.- 4.2. Las cecas y la delegación de la explotación minera en el Noroeste.- 4.3. Los poderes económicos regionales: obispos, ecclesiae y el control de la producción.- 5. Conclusiones.- 6. Bibliografía citada.

\section{INTRODUCCIÓN}

El estudio de las dinámicas de poder en el Noroeste de la Península Ibérica en época tardoantigua ha experimentado importantes avances en los últimos años. Frente a las visiones dominantes hace poco más de una década, aún ligadas al debate entre la feudalización del estado visigodo y el indigenismo de las estructuras sociales de estas zonas ${ }^{1}$, actualmente se observa un panorama interpretativo más rico y dinámico, pero también más complejo. Hay que destacar especialmente la revaloración del papel de las élites locales y el estudio de los mecanismos de su articulación con el poder central ${ }^{2}$, el reconocimiento de un elevado, aunque peculiar, grado de romanización de estas sociedades del Noroeste ${ }^{3}$, el dinamismo e interés del Reino suevo como estructura socio-política ${ }^{4}$, o el avance en el estudio de sus evidencias arqueológicas $^{5}$. Estas nuevas perspectivas nos ayudan a comprender mejor las estrategias y mecanismos de estructuración de los poderes locales y regionales, su variedad y dinamismo, y nos permiten empezar a comparar e integrar el cuadro del Noroeste tardoantiguo en los más amplios debates sobre las transformaciones sociales en Europa tras el fin del mundo romano ${ }^{6}$.

Sin embargo, a pesar de estos avances generales, quedan por comprender muchos aspectos fundamentales relativos a las bases y funcionamiento de los distintos poderes que operaban en esta zona de la Península, habi-

1 A. Barbero, M. Vigil, La formación.

2 S. Castellanos, I. Martín Viso, The local articulation; S. Orlowski, Fideles Regis; S. Castellanos, Ofensivas aristocráticas.

3 R. Menéndez, Reflexiones.

4 P.C. Díaz, El Reino Suevo; Idem, Extremis mundi.

5 J.A. Quirós, Early medieval; A. Rodríguez, Do imperio romano.

6 C. Wickham, Framing; G.P. Brogiolo, A. Chavarria, Aristocrazie e campagne. 
tualmente considerada "periférica", entre los siglos V y VIII. Uno de los más importantes son sus actividades económicas y fuentes de riqueza. Habitualmente, al hablar de la sociedad de época "germánica" en Gallaecia, se piensa en una sociedad ruralizada, con élites basadas en la captación, con mayor o menor éxito, de excedentes agrícolas. Sin negar la enorme importancia de la economía agraria en estas aristocracias, dicha caracterización parece cada vez más imprecisa e incompleta. Recientes trabajos desde la arqueología están aportando interesantes datos sobre otras actividades económicas en este período que sorprenden por su dinamismo, riqueza e intensidad, y que pueden cambiar nuestra percepción del alcance y características de estas élites. Destacan especialmente los avances en el conocimiento del comercio a larga distancia realizados por Adolfo Fernández, o el estudio del papel de la moneda visigoda en su sociedad, por Ruth Pliego. Sin embargo, estos progresos permanecen aún sin relacionar con otros interesantes indicios, materiales y textuales, de este período, y sin contextualizar en el discurso histórico global sobre el mismo.

En este trabajo pretendemos avanzar en el conocimiento concreto de las bases y actividades económicas, además de las agrícolas, de las élites de Gallaecia a partir de estos recientes avances, y, desde ellas, comprender mejor su poder social y político. Nos centraremos en un período específico, que es el que va entre inicios del siglo VI y mitad del siglo VII, en el que se puede constatar un importante, aunque peculiar y focalizado, sistema productivo-comercial de escala supralocal, en coincidencia con una época de especial dinamismo económico y político de Gallaecia.

Para lograr este objetivo, trataremos de combinar y poner en relación una amplia variedad de datos y fuentes de diverso tipo, habitualmente tratados por separado: evidencias de intercambios comerciales, acuñaciones monetarias, arqueología de las iglesias, de las fortificaciones, estudios paleoambientales, advocaciones religiosas y el análisis de fuentes escritas del período como el Parroquial suevo, la Vida de San Fructuoso y la "Autobiografía" de Valerio del Bierzo. A pesar de sus límites, consideramos que este tipo de aproximaciones interdisciplinares poseen un enorme potencial para el conocimiento de las sociedades altomedievales, como se tratará de mostrar aquí.

Por último, hay que señalar, que aunque el área de nuestro estudio será el Noroeste peninsular entendido como el territorio de la Gallaecia tardorromana y altomedieval (Galicia, Norte de Portugal, León y Occidente de Asturias, al margen de la expansión temporal de los límites meridionales a finales de la época sueva), la mayor parte de los datos arqueológicos en los que se basa este trabajo pertenecen a la actual Galicia, a los que se sumará la información textual y numismática de las zonas vecinas del Bierzo, León, Occidente de Asturias y la región de Tras-os-Montes en Portugal. 
2. LA CONSTATACIÓN DE UN SISTEMA PRODUCTIVO-COMERCIAL SUPRALOCAL EN EL NOROESTE PENINSULAR TARDOANTIGUO

\subsection{Comercio marítimo de larga distancia en la Gallaecia tardoantigua}

Sin lugar a dudas, uno de los descubrimientos más importantes en la arqueología del Noroeste en los últimos años ha sido la detección en el puerto de Vigo, a través principalmente de fragmentos de vajillas finas y ánforas de importación, de un intenso y dinámico comercio a larga distancia entre los siglos IV y VII. Este tema ha sido reciente y brillantemente estudiado por Adolfo Fernández, y por ello no vamos a entrar aquí en su descripción pormenorizada ${ }^{7}$. Únicamente esbozaremos ahora sus rasgos principales y su repercusión en el tema que nos ocupa, las dinámicas económico-políticas de las élites del Noroeste tardoantiguo.

El hallazgo en diversas excavaciones urbanas de una enorme cantidad de cerámicas de importación en Vigo revela la existencia de intensos y sostenidos intercambios comerciales entre Gallaecia y los mundos mediterráneo (Norte de África, Sur de la Península Ibérica y Mediterráneo oriental bizantino) y atlántico (Islas Británicas y Occidente de la Galia) en época tardoantigua. Esta doble conexión es la que otorga al yacimiento de Vigo un papel excepcional en los sistemas comerciales de la Tardoantigüedad, ya que funcionaría como nexo fundamental ("puerto de ruptura de carga") entre el comercio mediterráneo y atlántico ${ }^{8}$.

Los intercambios con el Mediterráneo parecen perdurar hasta algún momento de la segunda mitad del siglo VII. Por su parte, el comercio con el mundo atlántico presenta una menor intensidad global, pero irá cobrando un mayor protagonismo a lo largo de los siglos VI y VII, y podría tener una perduración mayor, llegando quizá incluso hasta fines del siglo VII inicios del VIII.

Según A. Fernández, los navíos provenientes del Mediterráneo llevarían hacia el Atlántico una carga heterogénea donde existiría un producto principal, que para la ruta con Oriente podría haber sido el alumbre o el vino, mientras que para la africana podría haberse tratado de cereales, y en momentos concretos, productos en ánforas (salazones y aceite). Los productos secundarios (complemento de carga) serían vajillas finas, lucernas, cerámicas comunes, objetos metálicos y otros pequeños productos de lujo. El cargamen-

7 A. Fernández, As relacións externas; Idem, Resultados preliminares; Idem, El comercio tardoantiguo.

8 A. Fernández, El comercio tardoantiguo, pp. 735-742. 
to de retorno, que es lo que en este trabajo nos interesará especialmente, se compondría de diversos productos de estas áreas atlánticas que harían rentable el largo viaje ${ }^{9}$.

Por tanto, la detección de este importante comercio tardoantiguo centrado en Vigo, abre un nuevo panorama de interpretación histórica, pero también de cuestiones que se deben resolver. En primer lugar, frente a la tradicional idea de periferia y aislamiento de Gallaecia, empezamos a comprender que el Noroeste estaba no solo conectado sino doblemente relacionado, a diferencia de la gran mayoría de zonas del antiguo imperio, tanto con el mundo mediterráneo como con el Atlántico. La constatación de la importancia de este comercio a larga distancia completa y termina de reforzar otras evidencias de influencias externas que ya se conocían previamente a nivel artístico ${ }^{10}$, religioso-eclesiástico ${ }^{11}$ o político ${ }^{12}$.

Sobre todo, hay que enfatizar que Vigo es el yacimiento donde más peso adquieren los materiales orientales de todo el Occidente tardorromano ${ }^{13}$, lo que indica unas relaciones especiales y preferentes de Gallaecia con el mundo Bizantino. Estas relaciones están claramente centralizadas en Vigo, ya que por el momento es el único yacimiento conocido en Gallaecia que continúa comerciando, y además de manera intensa, tras la mitad del s. VI, que es el límite para el resto de yacimientos productivo-comerciales de la costa galaica como A Lanzada o A Coruña, con el abandono de su importante faro durante ese siglo.

Esta cronología coincide, aproximadamente, con el final de las importaciones bizantinas en el suroeste británico. De hecho, Gallaecia pudo ser la competidora e incluso la culpable del final del interés bizantino en el Suroeste británico hacia mitad del siglo VI, ya que precisamente cuando finaliza el comercio del suroeste británico con Oriente, se relanza el galaico ${ }^{14}$. Quizá una razón digna de tenerse en cuenta es que solo desde mitad del siglo VI $G a$ llaecia, tras un siglo de silencio en las fuentes ${ }^{15}$, posee ya una organización, centralización comercial y estructuración interna lo suficientemente adecuada como para ofrecer a Bizancio los mismos productos que las Islas Británicas, y más cerca. Sabemos que el comercio en Britania estaba impulsado directa-

9 Ibidem, pp. 713-734.

10 R. Yzquierdo, Arte Medieval, pp. 58-70; M. Núñez, Arquitectura, p. 73-77.

11 M.C. Díaz y Díaz, La cristianización en Galicia, pp. 114-118.

12 L.A. García Moreno, Las relaciones internacionales.

13 A. Fernández, Resultados preliminares, p. 382.

14 E. Campbell, Continental and Mediteranean imports, A. Harris, Byzantium, Britain and the West.

15 P.C. Díaz, Extremis mundi.

ANUaRio de Estudios Medievales, 44/2, julio-diciembre 2014, pp. 983-1023

ISSN 0066-5061, doi:10.3989/aem.2014.44.2.10 
mente por el imperio bizantino, por lo cual no se puede descartar esta misma motivación para el caso del Noroeste peninsular.

Con respecto al tema que aquí nos ocupa, hay que señalar que al menos desde mitad del siglo VI este comercio exterior refleja un sistema económico peculiar, intenso pero aparentemente elitista y restringido dentro de Gallaecia, para el cual debían existir grupos específicamente dedicados a él. Fuentes de la época como las leyes visigodas hablan de la existencia de "transmarini negotiatores", seguramente griegos, judios y sobre todo sirios que probablemente habrían formado un asentamiento estable en Vigo, para organizar las mercancías llegadas desde otros puertos del norte (metales, madera tejidos, curtidos, cera, miel o esclavos), y vender o reexportar las mercancías provenientes de Oriente y Túnez (vino, aceite, alumbre, grano, y diversos objetos de lujo: vajillas finas, lucernas, objetos metálicos) ${ }^{16}$. Pero, junto a ellos, es evidente que existirían unas élites galaicas que dirigían la producción, distribución y preparación de las mercancías del Noroeste y comerciaban con estos mercaderes orientales. Por último, aunque no es el tema de este trabajo, no hay que olvidar que existiría una producción y un mercado interno propio galaico de cierta importancia.

A continuación vamos a tratar de acercarnos un poco mejor a la explotación y organización por parte de las élites galaicas de esa producción específica del Noroeste destinada a la exportación desde el puerto de Vigo entre los siglos VI y VII. Para ello debemos plantearnos en primer lugar cuáles serían esas mercancías galaicas, y dónde y cómo se producían.

\subsection{Actividades minero-metalúrgicas en el Noroeste tardoantiguo}

En primer lugar hay que hablar de uno de los productos más importantes y cotizados del Noroeste peninsular a lo largo de su historia: los metales, y de manera especial el estaño y el oro. El problema radica aquí en que la historiografía ha tendido tradicionalmente a negar, dada la falta de evidencias arqueológicas directas, la existencia de actividades mineras de mínima importancia en el Noroeste a partir del siglo III d.C., momento en que se abandonan las grandes explotaciones estatales del Alto imperio romano.

Así, especialistas en el período como P. C. Díaz subrayan la ausencia de evidencias de minería en este período, aunque admiten la posible continuidad de pequeñas explotaciones privadas en zonas marginales de la actual Asturias y O Courel (Lugo), así como un aprovechamiento de la extracción en

\footnotetext{
16 A. Fernández, El comercio tardoantiguo, pp. 735-742.
} 
los ríos ${ }^{17}$. También se ha considerado que las referencias de san Isidoro en sus Etimologías a metales y su obtención en el siglo VII no serían más que simples tópicos copiados de textos clásicos y se baraja que la mayor parte de la producción monetaria sueva y visigoda provendría casi enteramente de refundiciones de joyas y monedas preexistentes ${ }^{18}$. Esta imagen es compartida tanto en los estudios históricos de importantes zonas mineras del Noroeste como Valdeorras ${ }^{19} \mathrm{o}$ el área asturleonesa occidental ${ }^{20}$ como en las síntesis globales de la minería en la región ${ }^{21}$.

Sin embargo, hace ya años que algunos autores han señalado que la sociedad de época bajoimperial y suevo-visigoda habría mantenido o incluso aumentado su necesidad de metales (para útiles de trabajo, actividades militares, acuñaciones monetarias, objetos de lujo) y que, por tanto, debía de existir una correspondiente actividad minera, aunque no fuese necesariamente a gran escala. Estos autores han propuesto diversos indicios de esta continuidad de la actividad minera en época tardorromana y altomedieval: la gran densidad de tesorillos de monedas bajorromanas y, luego, de cecas suevas y visigodas en el Noroeste, la reocupación de castros en el siglo $\mathrm{V}$ en zonas mineras, las referencias de legislación minera en el Código de Alarico, la abundancia y riqueza de la orfebrería visigoda, y en fin, la propia complejidad de la sociedad visigoda que sin duda tendría los mecanismos necesarios para obtener los metales requeridos ${ }^{22}$.

Como muestran J. C. Edmonson o R. Francovich, esa aparente ausencia de evidencias arqueológicas se debe simplemente a que se han estudiado mucho más las grandes minas, típicamente altoimperiales, que las pequeñas explotaciones, y por tanto se ha enfatizado en exceso el fin de la producción en el siglo III. Los lugares de minería tardoantigua y altomedieval, habitualmente de tipo aluvial y a cielo abierto, dejan mucha menos (o ninguna) huella y por ello son muy difíciles de localizar, distorsionando nuestra visión de esta actividad $^{23}$. Por tanto, más que un fin en el siglo III, habría que hablar de una reestructuración de la producción, con un declive de la explotación a gran escala

17 P.C. Díaz, Acuñación monetaria, p. 369, notas 8-15.

18 R. Pliego, La acuñación monetaria, p. 122.

19 R. Gurriarán, Da prerromanización ao wolfram, pp. 33-37.

20 J.A. Gutiérrez, J.J. Argüello, J. Larrazabal, Minería y metalurgia, pp. 907-908.

21 F. Fernández Martínez, Minería de Galicia, p. 263.

22 J.C. Edmonson, Mining in the later Roman Empire, p. 98; O. Puche, J. Bosch, Apuntes sobre la minería visigótica, p. 198; J. López Quiroga, M. Rodríguez Lovelle, Cecas y hallazgos, pp. 435-436; J.M. Novo, Lugo en los tiempos oscuros, p. 256; M. Hardt, The accumulation of wealth, p. 254.

23 J.C. Edmonson, Mining in the later Roman Empire, p. 87; R. Francovich, Per una storia sociale, pp. 20-21. 
centralizada por el Imperio y un cambio a pequeñas explotaciones, que además se integraban mejor en la estructura socioeconómica local, de base agrícola ${ }^{24}$.

Pues bien, teniendo en cuenta todos estos precedentes, creemos que en la actualidad estamos ya en disposición de confirmar, de una vez por todas, la existencia de una actividad minera no despreciable ni residual -aunque nunca comparable a la minería altoimperial romana a gran escala-, entre por lo menos inicios del siglo VI y mitad del siglo VII en el Noroeste peninsular. Esto se debe a dos importantes y recientes constataciones:

En primer lugar, como ya hemos señalado, la propia detección del importante y dinámico comercio entre el puerto de Vigo y el mundo mediterráneo. Como indica quien mejor conoce este tema, A. Fernández ${ }^{25}$, los mercaderes del Mediterráneo, principalmente orientales (bizantinos), tan solo encontrarían justificación a un viaje tan largo en la búsqueda de una mercancía que no se puede hallar en el resto del Mediterráneo. Y precisamente sabemos que un metal tan codiciado como el estaño es específico de la Europa Atlántica: solo lo hay de manera importante en España, Bretaña, Suroeste de Britania y Sajonia, porque está asociado a granitos hercinianos, que escasean en el Mediterráneo ${ }^{26}$. De hecho, como es bien sabido, la fama del Noroeste peninsular como fuente de estaño proviene ya de época protohistórica. El estaño es fundamental para aleaciones, sobre todo de bronce, y por tanto se hacía imprescindible en la producción a gran escala de armas, objetos de lujo, etc, como la que el imperio Bizantino mantuvo en los siglos VI y VII. Junto al estaño, otro metal especialmente valorado del Noroeste es el oro, y parece muy probable que fuese comerciado también por los mercaderes mediterráneos. Este comercio tardoantiguo a larga distancia para la obtención de metales se ha constatado también en otras zonas atlánticas como el Suroeste de Britania ${ }^{27}$.

Pero al margen de esta evidencia indirecta, hay que subrayar sobre todo la importancia de algunos estudios de paleoambiente que han constatado un fuerte aumento de la contaminación por plomo en la atmósfera en el Noroeste peninsular debido a actividades minero-metalúrgicas entre los siglos VI y VII ${ }^{28}$. El plomo se libera tanto en los procesos de extracción del mineral como en los posteriores trabajos de fundición, y la intensidad de esa liberación a la atmósfera queda bien reflejada en los análisis de turberas. Los

24 J.C. Edmonson, Mining in the later Roman Empire, p. 98.

25 A. Fernández, El comercio tardoantiguo, p. 727.

26 C.J. Salter, Early tin extraction, p. 316.

27 Ibidem; A. Harris, Byzantium, Britain and the West; E. Campbell, Continental and Mediterranean imports; B. Cunliffe, Facing the Ocean, p. 478.

28 A. Martínez Cortizas et al., Paleocontaminación; A. Martínez Cortizas et al. Linking changes, p. 704; L. Moreno et al., Distribución de elementos traza, p. $125 .$. 
estudios dirigidos por A. Martínez Cortizas a partir de varias turberas de la Sierra del Xistral (Lugo) que representan niveles de actividad a escala regional, muestran cómo en época romana altoimperial los valores de actividad minero-metalúrgica en el Noroeste son muy importantes (fig. 1). Como era de esperar, a partir del siglo III d.C. empiezan a descender y se mantienen a la baja en los siglos IV y V. Sin embargo, y es lo que aquí nos interesa, vuelven a emerger aproximadamente desde fines del siglo $\mathrm{V}$ y registran un importante pico entre la primera mitad del siglo VI y mitad del VII. Esto coincide extraordinariamente bien con la cronología considerada para el apogeo del comercio constatado en Vigo, especialmente esa última e intensa fase de auge oriental. A partir del 640-650 caen bruscamente los valores de paleocontaminación, y no volverán a recuperarse, tímidamente, hasta el siglo IX. Como se puede ver, esta secuencia apoya un motivo principalmente exógeno y comercial para la actividad minero-metalúrgica del Noroeste tardoantiguo, ya que justo cuando se acaba la búsqueda de metales por el comercio mediterráneo, cae totalmente su extracción.

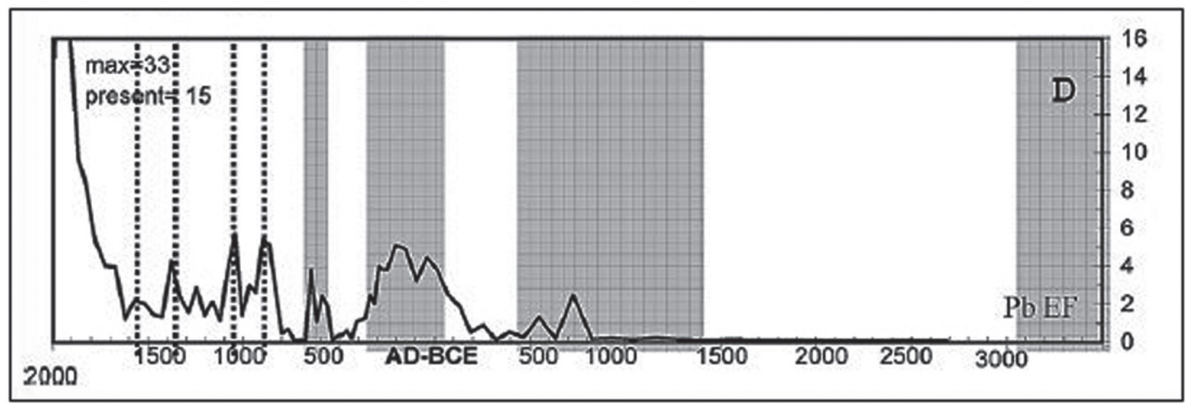

Fig. 1. Gráfica de los niveles de plomo en la atmósfera en los últimos 5000 años en el Noroeste de la Península Ibérica. Tomado de A. Martínez Cortizas et al., Linking, p. 703.

Junto a estas dos evidencias principales, encontramos una multitud de pequeños indicios históricos y arqueológicos que parecen reforzar y complementar la información sobre este sistema productivo-comercial que se desarrolló en algunas zonas del Noroeste durante casi 150 años, durante una de las etapas de transformación más importantes de los períodos antiguo y medieval. En las siguientes páginas trataremos de analizar estos indicios y explorar algunas vías de explicación del funcionamiento y características de dicho sistema económico. 


\section{EVIDENCIAS Y CARACTERÍSTICAS DE LA MINERÍA EN LA GALLAECIA TARDOANTIGUA}

\subsection{El contexto geográfico-arqueológico de la minería tardoantigua en el Noroeste peninsular}

La mayor parte de las áreas de minería de estaño están situadas en la zona occidental de Galicia, especialmente a lo largo de la dorsal que divide actualmente las provincias de Pontevedra y Ourense, y más cerca de la costa, en el entorno de Barbanza y en Santa Comba y Bergantiños, mientras que las minas de oro y estaño del interior están concentradas al sur de la provincia de Lugo y en la provincia de Ourense ${ }^{29}$. Pues bien, al observar en un mapa histórico estas áreas mineras, se observa una clara coincidencia entre muchas de estas zonas y un amplio número de evidencias arqueológicas, numismáticas y textuales de los siglos VI y VII (fig. 2). Hay que advertir que buena parte de estas evidencias presentan problemas, bien sea de precisión cronológica (en el caso de los datos materiales) o de identificación ${ }^{30}$ (en el caso sobre todo de las cecas y las iglesias del Parroquial suevo), por lo que deben considerarse de manera hipotética, como apoyo a la argumentación, pero no como una certeza. Por otro lado hay que señalar que la asociación espacial no implica, por supuesto, una relación temporal ni causal. Sin embargo, creemos que sí es indicativa su abundante recurrencia.

Comenzando por el suroeste de Galicia, hay que señalar que en el entorno inmediato de las minas de oro de O Rosal (Pontevedra) parece situarse a finales del siglo VI (ca. 570) la ecclesia Marciliana del Parroquial suevo ${ }^{31}$, que correspondería a la actual parroquia de Marzán. En este lugar hay restos de una villa romana, una necrópolis altomedieval y una posible iglesia dedicada a san Vicente, culto especialmente temprano ${ }^{32}$. A unos pocos kilómetros al norte están las minas de oro de Oia, en cuyo entorno se localizaría probablemente otra ecclesia del parroquial suevo llamada Turonio, que también será ceca visigoda durante el reinado de Recaredo (586-601) ${ }^{33}$. Se trata del actual lugar de Torroña (Oia, Pontevedra) $)^{34}$, a los pies de una fortificación tardoantigua y altomedieval ${ }^{35}$.

29 F. Fernández Martínez, Minería de Galicia, pp. 263-277.

30 Para la localización de las cecas seguimos las propuestas de R. Pliego, La moneda visigoda, mientras que para la identificación de las referencias del Parroquial Suevo recurrimos a diferentes autores que han estudiado cada diócesis y que serán indicados en cada caso concreto.

31 S. Vila, A diócese sueva, p. 87.

32 M.C. Díaz y Díaz, La cristianización en Galicia, p. 118.

33 R. Pliego, La moneda visigoda, p. 144.

34 S. Vila, A diócese sueva.

35 J. Garrido, Fortalezas, pp. 163-171. 


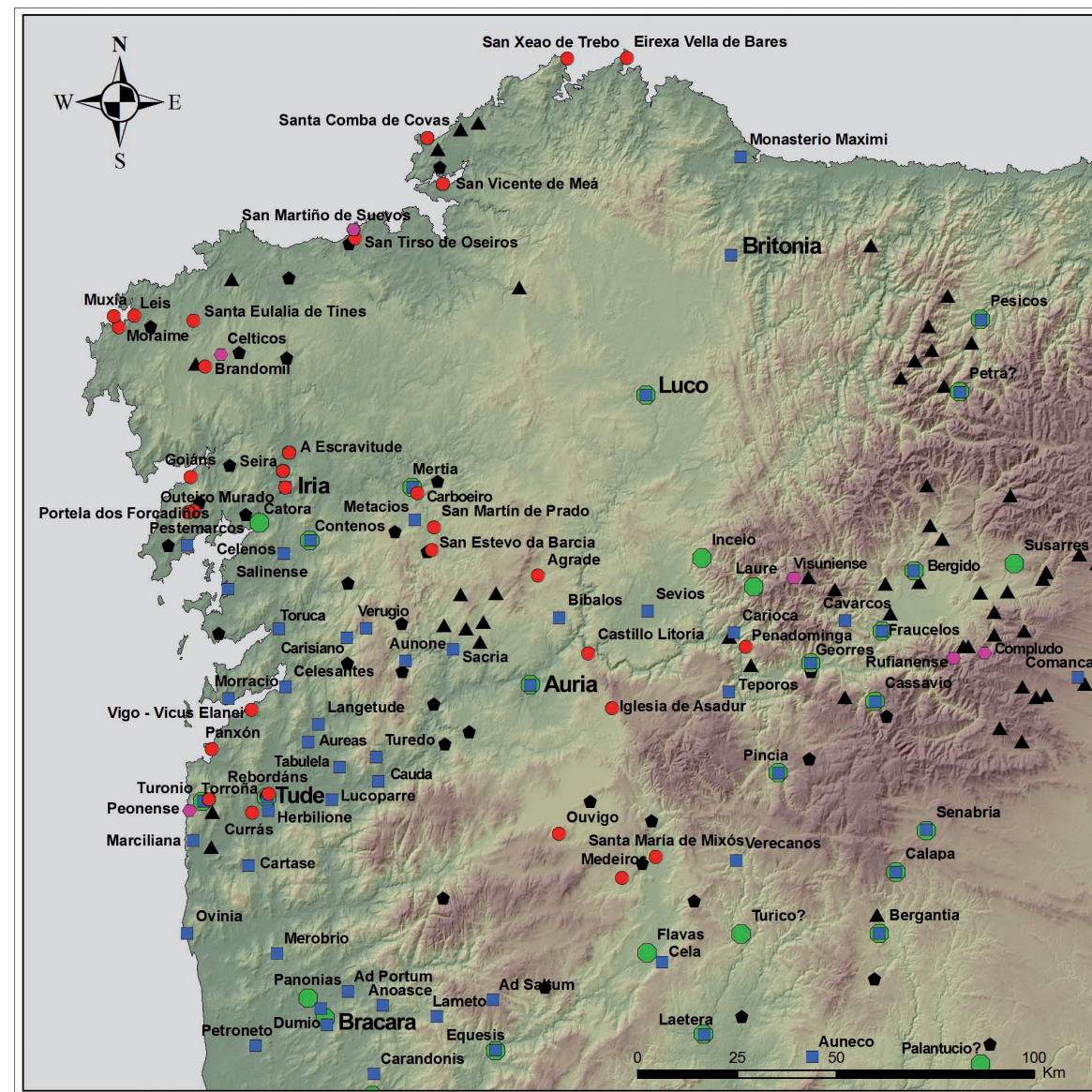

- Mina de estaño

A Mina de oro

\section{Ecclesia del Parroquial Suevo}

Ceca visigoda

- Evidencia arqueológica citada

- Evidencia textual/toponímica

Fig. 2. Mapa del Noroeste de la Península Ibérica con los sitios y yacimientos mencionados en el texto y su relación con las principales minas de oro y estaño (ampliado de F. Fernández, Minería, p. 267).

Remontando el río Miño hacia el interior encontramos las importantes minas de estaño de la comarca de Ribeiro. Algunas de las más importantes son las minas de Avión, cuyo topónimo parece corresponder a la ecclesia de 
Aunone que aparece en el Parroquial suevo ${ }^{36}$ y que quizá podría identificarse con la actual iglesia parroquial de Santos Xusto e Pastor de Avión, que es una advocación habitual de este período. Esta zona está bien comunicada con la costa a través del Miño, que en aquella época era navegable desde por lo menos ese punto hacia su desembocadura ${ }^{37}$.

Subiendo hacia el Norte, en las inmediaciones de las minas de estaño de Vila de Cruces y Fontao está la parroquia de Merza, documentada también como ecclesia de la sede de Iria en el Parroquial suevo, así como ceca y pequeño centro administrativo a finales del siglo $\mathrm{VI}^{38}$. También muy cerca de esas minas está el monasterio de San Lourenzo de Carboeiro, fundado en el año 936 sobre una estructura eclesiástica anterior que ha sido detectada arqueológicamente ${ }^{39}$. Esta zona está comunicada por el río Deza, que vuelca sus aguas en el Ulla y, desde ahí, llega al mar. Algo más al sur, en relación con las minas de estaño de Lalín hay evidencias arquitectónicas de posibles iglesias de este período en San Martín de Prado y San Estevo da Barcia ${ }^{40}$ y es probable que en ese entorno inmediato haya que localizar la ecclesia de Metacios, citada en el Parroquial suevo ${ }^{41}$. Una posibilidad podría ser el lugar de Taboada Vella (Silleda), en el que aparecieron restos de cerámicas tardoantiguas orientales focenses ${ }^{42}$. Esta zona también se comunica a través del río Deza con el Ulla y su desembocadura en Catoira.

Subiendo por la costa, la siguiente gran zona minera, también de estaño, es la península del Barbanza ${ }^{43}$. Concretamente, en la salida al mar más próxima a las ricas minas de estaño de Lousame está la iglesia de San Sadurniño de Goiáns (Porto do Son), documentada ya en el año $868^{44}$, y en la que se han localizado restos tardorromanos, una estela altomedieval ${ }^{45} \mathrm{y}$ un epígrafe referido a la consagración de una primitiva basílica cristiana sobre un bajorrelieve de influencias bizantinas ${ }^{46}$. En la salida al mar de otras minas estanníferas de Pobra do Caramiñal y Boiro, se encuentra la iglesia de San Isidro de Posmarcos que probablemente sea la heredera de la antigua ecclesia de los

36 S. Vila, A diócese sueva, p. 88.

37 J.L. Naveiro, El comercio antiguo, p. 138.

38 F. López Alsina, La ciudad, p. 157; R. Pliego, La moneda visigoda, p. 143.

39 A. Bonilla, Trabajos arqueológicos.

40 S. Feijoo, V. Rúa, La iglesia prerrománica.

41 F. López Alsina, La ciudad, p. 155; M.C. Díaz y Díaz, La Diócesis de Iria-Compostela, p. 18.

${ }^{42}$ J.L. Naveiro, El comercio antiguo, p. 244.

43 J.M. Álvarez-Campana, Contribución das minas.

44 F. López Alsina, La ciudad, p. 161.

45 F. Pérez Losada, Os asentamentos na Galicia, p. 439.

46 S. Vidal Álvarez, Frontal de sarcófago. 
Pestemarcos citada en el Parroquial suevo en torno al 570. Igualmente hay que señalar la importancia histórica del área de Catoira, que fue ceca visigoda a finales del s. $\mathrm{VI}^{47}$, y debió de constituir una salida al mar y lugar de control (teniendo en cuenta los cambios en el nivel del mar en los últimos siglos) de las minas de estaño de Rianxo. También hay que señalar que el topónimo de las importantes minas de estaño de San Finx (Lousame) remite a la dedicación a san Félix ${ }^{48}$, habitual en el siglo VII, como se observa, por ejemplo, en la “Autobiografía” de Valerio del Bierzo ${ }^{49}$.

En plena costa da Morte, hay que destacar el importante conjunto de evidencias de los centros eclesiásticos tardoantiguos de Moraime, Muxía y Leis, que suponen la salida al mar de las cercanas minas de estaño de Vimianzo (al interior, a unos 6-10 km de todas ellas). En San Xiao de Moraime (Muxía) se han excavado los restos de un asentamiento romano y una necrópolis altomedieval previos al conocido monasterio benedictino ${ }^{50}$. En esta necrópolis se halló también un broche de bronce, una pequeña cruz griega de bronce datable entre los siglos $\mathrm{V}$ y VII ${ }^{51}$ y restos de platos de vidrio de probable uso litúrgico ${ }^{52}$, todos ellos de probable cronología "visigoda". Estos materiales, las características del lugar y su advocación a San Julián, nos hacen pensar en la existencia de un monasterio altomedieval y, quizá, tardoantiguo. Aunque la excavación no confirmó este extremo, sí se habla de "otros muros de técnica constructiva distinta que se considera pueden pertenecer al antiguo monasterio altomedieval" ${ }^{53}$. Cerca de allí, en el atrio de la iglesia de San Pedro de Leis (Muxía) apareció un bajorrelieve paleocristiano de un crismón con alfa y omega, probablemente importado, dada su calidad, y datable en torno al siglo $\mathrm{VI}^{54}$. Por último, en la próxima iglesia parroquial de Santa María de Muxía hay dos posibles capiteles "germánicos" 55 .

Más al norte, cerca de la actual ciudad de A Coruña están las minas de oro y estaño de Carballo-Arteixo. Aquí podemos destacar las evidencias de San Tirso de Oseiro, al lado de las minas de estaño de Arteixo. Se trata de una iglesia constatada ya en el año $868^{56}$, en la que se han hallado materiales tardorromanos y dos sarcófagos de granito con una lauda de estola

47 R. Pliego, La moneda visigoda, pp. 143-144.

48 F. Cabeza, Toponimia de Galicia, p. 570.

49 R. Frighetto, Valério do Bierzo, p. 113.

50 M. Chamoso, Excavaciones arqueológicas; J. Carro, Tres esqueletos.

51 R. Brañas, Cruz de Moraime.

52 R. Yzquierdo, Arte Medieval, pp. 68-69.

53 M. Chamoso, Excavaciones arqueológicas; M. Núñez, Arquitectura, pp. 67-69.

54 J. Suárez Otero, Crismón de San Pedro, p. 91.

55 R. Yzquierdo, Arte Medieval, p. 57.

56 F. López Alsina, La ciudad, p. 161.

ANUaRio de Estudios Medievales, 44/2, julio-diciembre 2014, pp. 983-1023 ISSN 0066-5061, doi:10.3989/aem.2014.44.2.10 
que indica un cierto nivel de riqueza y estatus social ${ }^{57}$. También es muy interesante la relación entre las minas de estaño de Arteixo y el cercano pequeño puerto natural de San Martiño de Suevos, cuyo interesante topónimo parece remitir a este período tardoantiguo ${ }^{58}$. Al sur se encontraría la ecclesia de Celticos (aunque se trata de una interpolación al Parroquial suevo, parece realizada en una época temprana, probablemente en el propio siglo VII $)^{59}$ que posee en su entorno varias de las principales explotaciones de estaño en Galicia.

Siguiendo al norte, encontramos el filón de oro de la zona de FerrolPrior. En esta área se ha excavado la ermita de la isla de Santa Comba en Cobas (Ferrol), en la que se han documentado restos de un castro con importantes actividades metalúrgicas y una posterior fase de ocupación altomedieval, según la cerámica recogida ${ }^{60}$, durante la cual se construiría un pequeño cenobio, siguiendo influencias del cristianismo atlántico o "céltico" de este período. La primera mención segura a la iglesia es de 1110, pero es probable que sea la ecclesia in insula Selima del año $868^{61}$. Este enclave también posee varios filones de cobre y hierro, y probablemente el propio topónimo de la parroquia, "Covas derive" de actividades mineras.

Dejando ya la costa y dirigiéndonos hacia el interior, uno de los centros más importantes de minería aurífera de Galicia es la zona de Quiroga (Lugo), que corresponde a la ecclesia y ceca de Carioca durante los siglos VI y VII. En la iglesia-santuario de Santa María de A Ermida, inmediata a la capital municipal se conservaba un crismón cristiano del s. V (con referencias precisamente al oro y la plata) así como dos bases de columnas y un capitel clásico en mármol, de importación ${ }^{62}$. Cerca de Quiroga se encuentra otro de los centros fundamentales de explotación aurífera: O Courel (Lugo), que probablemente corresponde a la ceca sueva y visigoda (y posterior territorio altomedieval) de Laure.

Otra de las zonas mineras gallegas por excelencia a lo largo de la historia es la comarca de Valdeorras ${ }^{63}$. Se identifica con la ecclesia de Geurros, que también se constata como ceca visigoda desde el reinado de Recaredo hasta Suintila ${ }^{64}$. Es probable que la capital de este distrito se encontrase en la

57 M. Núñez, Arquitectura, p. 69.

58 F. Cabeza, Toponimia de Galicia, p. 64.

59 F. López Alsina, La ciudad, p. 155.

60 A. González, Intervención arqueológica.

${ }^{61}$ F. López Alsina, La ciudad, p. 161.

62 A. Rodríguez, Historia del arte romano, p. 420.

63 R. Gurriarán, Da prerromanización ao wólfram.

${ }^{64}$ J.C. Rivas, Antigüedad del episcopado, p. 132; R. Pliego, La moneda visigoda, p. 138. 
actual parroquia de Santa María de A Proba, donde se ha constatado un amplio asentamiento romano, y en cuyo entorno hay abundantes restos de época tardoantigua, como las placas de canceles visigodos encontrados respectivamente en la iglesia de Santa Comba de Córgomo (junto a una de las principales minas de oro de toda Galicia) y San Miguel de Xagoaza ${ }^{65}$. A unos $20 \mathrm{~km}$ al sureste se encontraba la ecclesia y ceca de Cassavio, en la actual parroquia de Santa María de Casaio ${ }^{66}$ (Carballeda de Valdeorras, Ourense), muy cerca de la actual frontera con León. Se trata de otra importante zona minera, con una de las mayores canteras de pizarra del mundo, pero también con abundante estaño.

En el entorno minero del Valle del Medo, con explotaciones a cielo abierto y bien comunicado por la vía XVIII, está la iglesia de Asadur, en la que se conserva un bajorrelieve de granito que representa una crucifixión y una inscripción en letra visigótica. Según J. Delgado esta pieza se puede datar en el siglo VII, y pertenecería a un pequeño templo de finales del siglo $\mathrm{VI}^{67}$.

A los pies de las minas de estaño de Verín está Santa María de Mixós, iglesia con diversos elementos prerrománicos ${ }^{68}$. Aunque es probable que se reconstruyese profundamente en el siglo $X$, podría haber un templo o monasterio visigodo previo ${ }^{69}$ ya que su sillería es posiblemente reutilizada. Hacia oriente, ya en Viana do Bolo, está la ecclesia y ceca de Pintia, actual parroquia de Santa María de Pinza ${ }^{70}$, que nuevamente corresponde a las inmediaciones de varias explotaciones de estaño.

Ya fuera de Galicia, pero próximas a sus límites, habría que citar las minas de oro situadas en el entorno inmediato de los famosos cenobios de Compludo y San Pedro de Montes en el Bierzo fundados por san Fructuoso a mitad del siglo VII ${ }^{71}$. También muy cerca estaría la ceca y parroquia sueva de Fraucello, probablemente situada en el valle de Ulver, entre Ourense y León, en una zona de abundantes minas de oro $^{72}$. Como es sabido, otras cecas y ecclesiae del Noroeste como Bergidum o Pesicos se sitúan en enclaves mineros de primer orden, especialmente ligados a la extracción aurífera. Lo mismo sucede en la zona noreste de Portugal (Tras-os-montes), donde gran parte de

65 A. Rodríguez, S. Ferrer, I. García, Priorato de Xagoaza, pp. 80-87.

66 J.C. Rivas, Antigüedad del episcopado, p. 132; R. Pliego, La moneda visigoda, p. 138.

67 E. Rivas, J. Delgado, Un bajorrelieve.

68 J. Lorenzo Fernández, La iglesia prerrománica.

69 M. Núñez, Arquitectura, p. 202; A. Rodríguez, Historia del arte romano, p. 471; R. Yzquierdo, Arte Medieval, pp. 140-144.

70 R. Pliego, La moneda visigoda, p. 139; J.C. Rivas, Antigüedad del episcopado, p. 132.

71 M. C. Díaz y Díaz, La Vida de San Fructuoso.

72 R. Pliego, La moneda visigoda, p. 141. 
las ecclesiae citadas en el Parroquial suevo ${ }^{73}$ y sus posteriores identificaciones como cecas visigodas ${ }^{74}$ están vinculadas claramente a minas, como sucede con Laetera, Equesis, Flavas (Chaves), Bergantia (Braganza) y quizá Palantucio, todas ellas relacionadas con importantes filones de estaño ${ }^{75}$.

La abundancia de esta vinculación "yacimiento tardoantiguo-entorno de minería de oro y estaño" nos hace pensar que, al menos en algunos de los casos expuestos, esconde más que una simple coincidencia espacial. Sobre todo teniendo en cuenta que en la mayor parte de los casos se trata de zonas aparentemente "periféricas" de Galicia y que, por otro lado, este tipo de datos históricos y arqueológicos apenas aparecen en otras zonas "periféricas" que no poseen recursos mineros.

\subsection{Explotación y distribución de la producción metalífera}

¿Cómo se organizaba y articulaba en la Galicia de los siglos VI y VII la producción y distribución de metales para su exportación? Por desgracia, no contamos con ningún dato directo que nos permita reconstruir con cierta seguridad este sistema económico, aunque sí hay diversos indicios sobre los que formular algunas hipótesis de trabajo.

Como ya se ha señalado, la minería de este período no deja apenas huella, aunque parece probable que se trate de explotaciones de pequeño tamaño, principalmente a cielo abierto y sobre todo de yacimientos primarios. Pero no por ello esta actividad debe ser considerada "marginal". De hecho gracias a la precisión de las mediciones paleoambientales obtenidas ${ }^{76}$ podemos calibrar y comparar su intensidad sin temor a exagerar su importancia. Aunque esta producción no llega, obviamente, a alcanzar los niveles de la gran explotación romana altoimperial (principalmente de oro) de los siglos I-II e inicios del III, sí es comparable a la intensidad que las explotaciones tenían en torno al cambio de Era o a finales del siglo III d.C. (fig. 1). Es decir, se trata de una actividad mucho más importante que una mera "producción residual" y es necesario tratar de comprenderla y contextualizarla, algo que hasta ahora no se ha hecho.

Dada la falta de datos directos, las referencias de la etnografía pueden aportar algunas ideas sobre su funcionamiento. Son especialmente interesantes los estudios de etnoarqueología de las pequeñas explotaciones del

73 J.Alarcao, As paróquias suévicas.

74 R. Pliego, La moneda visigoda, pp. 127-131.

75 Ibidem, p. 131, J. Alarcao, As paróquias suévicas.

76 A. Martínez Cortizas et al., Linking changes. 
estaño en época preindustrial en la costa del Barbanza ${ }^{77}$, ya que se asemejan enormemente a las descripciones de san Isidoro en el siglo VII: se trataba principalmente del lavado manual del mineral que llega a la playa por aluvión erosional, y que el agua de mar saca a la luz cuando baja la marea ${ }^{78}$. En esta zona se conserva la memoria popular de cómo hasta hace unos 50 años se recogían en la playa piezas de escoria -a veces incluso estaño puro-, que luego se lavaban, separaban y se embarcaban en grandes barcazas hacia Vilagarcía o Pontevedra, donde se procedía a su preparación y exportación. En otros casos se realizaban pequeñas zanjas a cielo abierto para extraer el mineral ${ }^{79}$. Esto último ocurriría también en las zonas de interior tras el fin de las grandes explotaciones altoimperiales, con la continuidad de las técnicas más sencillas de explotación como los cortes a cielo abierto o el bateo en los placeres fluviales, que aun existían en Valdeorras hace 60 años ${ }^{80}$. Se trata en todos los casos de sistemas de extracción sencillos, que no precisan de gran inversión tecnológica y que apenas dejan evidencias materiales. Su pequeña producción individual podría suplirse con una amplia multiplicidad de explotaciones dispersas, de manera similar a lo que ocurre con las cecas visigodas, como veremos más adelante.

Tampoco poseemos datos específicos sobre los procesos de fundición, almacenaje y posterior transporte de la producción. En todo caso, podemos pensar que al menos algunas de las abundantes evidencias de estructuras eclesiásticas tardoantiguas en estos entornos mineros podrían ser reflejo de la actividad de un centro económico en su entorno durante los siglos VI-VII, aunque las huellas del mismo sean menos visibles que el edificio religioso. No se trata necesariamente de considerar las iglesias y monasterios como una pieza concreta de este sistema económico (extractivo, productivo y comercial), pero sí un reflejo de su dinamismo, y del nivel económico de sus dirigentes.

Este fenómeno es especialmente evidente en los entornos mineros y productivos de la costa, que como hemos visto, se pueden relacionar en todos los casos con evidencias de estructuras eclesiásticas coetáneas: Moraime (Muxía), Panxón (Nigrán), Goiáns (Porto do Son), y quizá San Xiao de Trebo (Cariño), Catoira (Catoira), Santa Comba de Cobas (Ferrol) ${ }^{81}$. Creemos que estas iglesias pueden entenderse como los centros religiosos de un pequeño complejo productivo-mercantil aristocrático de los siglos VI y

77 X. Ayán et al., Etnoarqueoloxía.

78 O. Puche, J. Bosch, Apuntes sobre la minería visigótica, p. 206.

79 J.M. Álvarez-Campana, Contribución das minas, p. 37.

80 R. Gurriarán, Da prerromanización ao wolfram, p. 23.

81 J.C. Sánchez, Arqueología de las iglesias.

ANUARIO de Estudios Medievales, 44/2, julio-diciembre 2014, pp. 983-1023 ISSN 0066-5061, doi:10.3989/aem.2014.44.2.10 
VII. Pero además, como se ha podido comprobar, muchas de estas iglesias tardoantiguas en la costa del Noroeste se construyen sobre antiguas villas y factorías romanas dedicadas a la producción y comercio, sobre todo de salazones. Habitualmente se interpretaba el fin de la producción de estas villas y factorías entre los siglos V-VI, como una crisis que conllevaba el cese de la actividad económica de carácter extralocal en ese lugar ${ }^{82}$. Sin embargo, cada vez parece más evidente que en algunos casos otra actividad productivacomercial sustituyó a la antigua producción tardorromana. Productos como las salazones o salsas de pescado ya no serían la mercancía demandada en un contexto comercial internacional cada vez más restringido, sino que los mercaderes mediterráneos que llegaban al Noroeste desde mitad del siglo VI buscarían productos muy lucrativos y específicos de estas zonas atlánticas como los metales, la madera o las pieles. Por eso, muchos propietarios (sean individuales o grandes propietarios episcopales, con múltiples propiedades) tratarían, si aun eran capaces, de reorientar su producción o actividad hacia alguno de estos sectores según las características y recursos de sus propiedades. En algunos casos se trataría de la fundición y distribución de metales, como en los casos señalados previamente. En otras zonas alejadas de las áreas mineras, se podrían embarcar productos como pieles o madera. Quizá esto último suceda en San Vicente de Adro Vello (O Grove), San Xiao-Pipín (Cangas), Bares (Mañón) y quizá San Vicente de Meá (Mugardos) ${ }^{83}$. En todos estos pequeños centros se concentraba la producción local y se embarcaba hacia Vigo, donde se acumulaba y preparaba para su exportación a la llegada de los navíos mediterráneos.

Estos casos son especialmente reconocibles en la costa, debido a las características de su emplazamiento y estructuras físicas de las antiguas factorías. Pero en el interior podría ocurrir lo mismo, aunque quizá menos frecuentemente ya que sería más difícil que se reuniesen las condiciones para que el antiguo establecimiento siguiese siendo rentable dentro del nuevo contexto geográfico-económico de comercio exterior de los siglos VI y VII, más reducido y focalizado que uno o dos siglos antes. Actividades de producción y fundición de los metales podrían desarrollarse en centros como San Vicente de Marzán (O Rosal) o Santo Tirso de Oseiro (Arteixo), cerca de filones mineros de oro y estaño respectivamente. Otras actividades económico-productivas podrían haberse dado en sitios como Currás (Tomiño), Ouvigo (Blancos), San Vicente de Agrade (Chantada) o Santa Eulalia de Tines (Vimianzo), en los que de nuevo se constata la probable creación de una

82 D. Bernal, Iglesia, producción.

83 J.C. Sánchez, Arqueología de las iglesias. 
iglesia sobre una villa y factoría tardorromana en este período ${ }^{84}$. Es probable que estas producciones de interior bajasen a menudo hacia la costa a través de los principales cauces fluviales, como sucedería con aquellas explotaciones mineras de la zona de Silleda-Lalín (a través del río Deza y luego el Ulla hasta Iria Flavia). Las producciones de la zona de Ribeiro y Rivadavia, lo harían a través del Miño que en época antigua era navegable desde la ciudad de Ourense (Auria). Las minas de Quiroga y Valdeorras utilizarían el trazado de la vía XVIII (con posibles ayudas puntuales de los tramos navegables del río Sil) hasta la ciudad de Ourense, en las que se embarcaban hacia Tui, antes de su envío a Vigo.

Esta hipótesis explicaría la paradoja de porqué, por un lado, se abandonan las áreas productivas romanas, pues ya no eran necesarias (por ejemplo, las piletas de salazón) pero a la vez, muy poco tiempo después, se crean iglesias sobre ellas, indicando un poder económico que sigue actuando en su entorno, y no un mero abandono. Se trata de una reorientación económica hacia otras actividades que, sin embargo, dejan menos huella. Un ejemplo especialmente interesante en Asturias es el complejo metalúrgico tardoantiguo ligado a una estructura eclesiástica sobre la antigua villa romana de Veranés (Gijón) ${ }^{85}$. Quizá en ese sentido haya que interpretar también la pequeña explotación minera de A Lagoa-Vacariza muy cerca de la villa tardorromana e iglesia altomedieval de San Xiao de Trebo ${ }^{86}$. En otras zonas de la Europa Atlántica de este momento tenemos paralelos interesantes del papel productor y comercial de los monasterios y centros eclesiásticos, como pequeños complejos económicos de su entorno ${ }^{87}$, especialmente en la costa y en los principales ríos ${ }^{88}$.

A lo largo de esta geografía de explotación y distribución podrían existir algunos puntos de control y vigilancia. De manera hipotética, podemos relacionar algunas evidencias sobre fortificaciones y "reocupaciones" de recintos fortificados durante este período con el control de la extracción o circulación de los metales. Un ejemplo es el de Penadominga (Quiroga), un posible castro minero situado en emplazamiento muy prominente, en el que se localizaron cerámicas "tardías" y dos placas de cinturón de bronce de tipo visigodo fechables entre los siglos VI-VII. Este castro, en el corazón de una rica zona minera, controla el río Sil y la vía romana a sus pies, y conserva el

84 Ibidem.

85 C. Fernández Ochoa et al. La villa romana de Veranés.

86 E. Ramil, Historia de Cariño, pp. 66-67.

87 E. Campbell, Continental and Mediterranean imports, p. 140.

88 S. Lebecq, The role of the monasteries. 
grabado de un tablero de juego que suele asociarse a guardias y vigilantes ${ }^{89}$. Otros puntos de control podrían situarse en pasos claves de la producción metalífera, como la importante unión de los ríos Sil y Miño, cerca de la cual está el Castellum Litoria (Nogueira de Ramuín), al lado del monasterio de San Estevo de Ribas de Sil, con una amplía visibilidad sobre éste y el entorno del encajonado paso del río. Se trata de un castro de finales de la Edad de Bronce, que se reocupa en época tardoantigua ${ }^{90}$. En su interior hay una inscripción que, según el detallado análisis de J. Freire Camaniel $^{91}$, podría ser perfectamente la un duque del rey visigodo Leovigildo, en torno al 585 o 586 . Por otro lado, en el entorno inmediato de las minas de oro de Oia están los restos de una fortificación altomedieval, denominada castillo de Torroña, que goza de una gran visibilidad hasta la desembocadura del Miño. Quedan restos de la atalaya, de dos niveles y realizada en mampuestos colocados en seco, con una tipología anterior al siglo $\mathrm{X}-\mathrm{XI}^{92}$. Por último en la península del Barbanza, en torno a las importantes minas de estaño de Boiro se encuentran varias fortificaciones que no han podido todavía ser correctamente datadas, como el recinto de Outeiro Murado, con una muralla construida en seco que cubre una planicie de unos 60 metros de largo, y la fortificación de Portela dos Forcadiños, en la misma entrada de una mina ${ }^{93}$.

\section{PODER Y ARTICULACIÓN ECONÓMICA EN LA GALLAECIA TARDOANTIGUA}

\subsection{La monarquía suevo-visigoda y la minería en Gallaecia}

A pesar de sus evidentes límites y problemas, consideramos que, en su conjunto, las evidencias hasta ahora expuestas muestran la existencia de una actividad minero-metalúrgica destinada a la exportación en la Gallaecia de los siglos VI-VII. A partir de esta base trataremos de aproximarnos algo mejor a la organización socioeconómica de los grupos que dirigían este sistema.

La primera cuestión es: ¿quién dirigía este circuito productivo-comercial? Ante todo es evidente que esta actividad y sus beneficios estaban en manos de élites con un nivel económico relativamente alto. Esto se observa en diversos indicios arqueológicos ya mencionados, como los propios

89 R. Yzquierdo, Arte Medieval, p. 66.

90 J. Lamas, Actuación arqueolóxica.

91 J. Freire, ¿Un testimonio epigráfico?

92 J. Garrido, Fortalezas, pp. 163-171.

93 http://www.manuelgago.org/blog/ [consulta: entre julio y septiembre de 2011]. 
productos obtenidos en estos intercambios, que corresponden a mercancías exóticas y de prestigio (vinos orientales, vajillas de lujo, objetos metálicos), o la frecuente relación entre puntos clave de este sistema económico y la fundación de estructuras eclesiásticas, que de nuevo indican una cierta capacidad económica. A esto habría que añadir, como hipótesis a corroborar, que buena parte de las llamadas "laudas de estola" de este período, consideradas como un enterramiento de alto nivel social, aparecen mayoritariamente en zonas de producción y distribución de este sistema económico como Iria, Vigo, Rebordáns, Seira, A Escravitude, Medeiros, Oseiros, Panxón o Brandomil ${ }^{94}$.

Pero, más concretamente, existen diversas evidencias que hacen pensar que este sistema económico estaba controlado en última instancia, de manera directa o indirecta, por la monarquía y los principales poderes de $\mathrm{Ga}$ llaecia vinculados a ella, especialmente las jerarquías eclesiásticas. Veamos dichas evidencias:

En primer lugar, como señalan diversos autores, Gallaecia era un área de especial concentración de fundi del fisco regio hispanovisigodo, en gran medida como herencia de la importancia de las explotaciones imperiales romanas en áreas como el Bierzo o Valdeorras ${ }^{95}$. Por ello, aunque podrían existir minas privadas, es probable que muchas de las minas estuviesen en manos de la monarquía, que las habría heredado del fisco imperial.

En segundo lugar, como ya hemos visto, parece muy probable que esta actividad económica estuviese especialmente dedicada y movida por la demanda de un gran protagonista internacional, el Imperio Bizantino (como se ve en los materiales orientales y en la perfecta coincidencia de las cronologías de su presencia comercial con la producción y su interrupción por la expansión árabe a mitad del siglo VII), con el que la monarquía sueva y visigoda mantienen importantes pactos y tensiones durante todo este período ${ }^{96}$. Además, este comercio con Bizancio se concentra, desde mitad del siglo VI, únicamente en Vigo frente a la diversidad de enclaves y actores del anterior comercio tardorromano, justo en el momento en que la Gallaecia sueva estaba experimentando un importante proceso de organización y fortalecimiento administrativo interno ${ }^{97}$. Ese carácter tan específico, centralizado y de importantes implicaciones político-económicas de este sistema económico hace pensar de nuevo en un cuidadoso control del mismo por parte de la monarquía suevovisigoda.

94 M. Chamoso, Sobre las necrópolis, J. Suárez, Sobre las laudas.

95 R. Frighetto, Valério do Bierzo, p. 13, 41.

96 L.A. García Moreno, Las relaciones internacionales.

97 P.C. Díaz, Extremis mundi, Idem. El reino suevo. 
En tercer lugar, la posible existencia de una serie de fortificaciones y quizá atalayas de señales -representadas por los abundantes topónimos "faro" en las cumbres gallegas ${ }^{98}$ - a lo largo de los principales ejes de producción y distribución de este sistema también apoyaría la idea de que no se trataba de un conjunto de particulares aislados sino de un control supralocal y bien estructurado de su conjunto.

En cuarto lugar, el paralelo de otras zonas atlánticas de explotación minera y comercio con el Mediterráneo oriental, precedentes directas del sistema de Gallaecia, también remiten a un estricto control supralocal. Es el caso del Oeste de Gran Bretaña e Irlanda, donde el comercio se dirigía y centralizaba en sitios reales o de alto status, en los que se observa la concentración de riqueza en forma de metales preciosos, producción centralizada, especialización artesana y control de la redistribución ${ }^{99}$. Aunque, obviamente, el Noroeste de la Península Ibérica responde a un contexto y estructura más romanizados, complejos y articulados, parece probable que también existiese un cuidadoso control de esta producción e intercambios.

Sin embargo, esto no implica que la monarquía sueva o visigoda explotase y comerciase directamente estos recursos, sino que es más plausible un sistema de delegación real a una serie de élites locales. Como han propuesto algunos autores, es posible que el rey autorizase la explotación de una mina mediante una donación, reservándose el cobro de sus derechos, o bien una concesión por arriendos temporales, como sucedía durante el Bajo Imperio, y no es descartable incluso que en este período naciesen las bases de la posterior regalía minera medieval ${ }^{100}$. Como veremos más adelante, esta delegación se plasmaba a través de un pacto fiscal, a menudo (aunque no siempre) representado por la acuñación de moneda.

¿Quiénes son esas élites económicas locales y cómo se articulaba su relación con la monarquía? Esta pregunta se basa en la interesante perspectiva, formulada por S. Castellanos y I. Martín Viso, del estudio de las vinculaciones entre poderes locales y supralocales en este período ${ }^{101}$. Aunque contamos con escasos datos para responderla, sí es posible al menos proponer varias ideas de trabajo en base a la combinación de fuentes, textuales y arqueológicas.

98 R. Martí, Los faros.

99 E. Campbell, Continental and Mediteranean imports, pp. 140-141.

100 O. Puche, J. Bosch, Apuntes sobre la minería visigótica, p. 216.

101 S. Castellanos, I. Martín Viso, The local articulation. 


\subsection{Las cecas y la delegación de la explotación minera en el Noroeste}

En primer lugar, el estudio de los lugares de acuñación de moneda visigoda en el Noroeste, a partir del año 585, nos ayuda a explorar algunas pistas de cómo se organizaba a escala local este sistema económico y de su articulación con los poderes centrales que, en última instancia, eran propietarios de gran parte de las zonas mineras. Afortunadamente, el papel de la moneda y sus centros de acuñación en la sociedad hispanovisigoda ha sido reciente y ampliamente estudiado por R. Pliego Vázquez ${ }^{102}$, lo que nos permite trabajar con un mapa de cecas actualizado y sensiblemente diferente al utilizado en los últimos 60 años a partir de la obra de G. Miles.

Es conocida la alta densidad de cecas visigodas que se constatan en el Noroeste de la Península Ibérica y que supone la mitad del total de cecas documentadas en la Hispania visigoda ${ }^{103}$. Igualmente interesante es comprobar cómo la inmensa mayoría de estas cecas en la Gallaecia nuclear entre la conquista de Levogilido en 585 y el reinado de Chindasvinto (642-649) corresponden o bien a núcleos principales o bien a lugares con importante riqueza minera, aunque la bibliografía, por las razones ya expuestas, se ha resistido una y otra vez a poner en relación minería y acuñación. Así, junto a una serie de núcleos principales que acuñan moneda (Lugo, Aurense, Tude, Braga) aparecen en el Noroeste una amplia serie de pequeñas y dispersas cecas situadas siempre en zonas de actividad minera, tanto de oro: Laure (Folgoso do Courel), Pincia (Pinza), Cassavio (Casaio), Fraucello (valle de Frogelo), Bergio (Bierzo), Georres (A Pobra de Valdeorras), Calapa (Calabor), Pesicos, Petra o Susurres, como de estaño: Catora (Catoira), Mertia (Merza), Bergantia (Braganza), Flavas (Chaves), Ewesis, Turico, Palantucio y Laetera ${ }^{104}$. Tan solo no se constata esta relación directa en el caso de Contenos, aunque no está lejos de la minería del entorno de Iria y de Merza, -además de ser un enclave viario de gran importancia-, y en el caso de Inceio (O Incio) que de todos modos sí posee ricas canteras de mármol y vetas de hierro.

Sin embargo hay que recordar que la moneda visigoda no posee una función comercial, y por ello estas cecas no reflejan una estructura de intercambios. Por el contrario la moneda en este período es ante todo un elemento de vinculación político-fiscal, y en ese sentido, lo que más bien nos está indicando esta coincidencia de áreas de actividad minero-metalúrgica y

102 R. Pliego, La acuñación monetaria.

103 P.C. Díaz, Acuñación monetaria.

104 R. Pliego, La moneda visigoda; J. Alarcao, As paróquias suévicas. 
acuñación monetaria, es la existencia de auténticas bisagras de articulación con la monarquía ${ }^{105}$. Las cecas no son una expresión directa ni reflejan una relación de causa-efecto de la actividad minera, ya que responden a una realidad político-económica más amplia y compleja, pero sí reflejan un pacto, una articulación entre un poder local y el poder monárquico. Y es dentro de ese pacto donde entra la concesión de una actividad económica, que en estos casos sería sin duda la minería. Por tanto, no todas las cecas responden a la minería, pero sí nos parece probable que la delegación de la actividad minera que existió quedase reflejada a través de las cecas. Esto explica la existencia de tantas acuñaciones en lugares aparentemente "periféricos" de la articulación del reino suevo y visigodo, especialmente cuando no tenemos noticias ${ }^{106}$ de cecas en algunas zonas dinámicas y densamente pobladas como el entorno de Tui, y en general la parte suroccidental de Galicia, donde en cambio sí se constata una gran densidad de ecclesiae del Parroquial suevo y donde, por ejemplo, existía la mayor concentración de villae tardorromanas de Galicia.

En este sentido, tampoco parece casualidad que precisamente a mitad del siglo VII, cuando se detecta el fin del comercio con el Mediterráneo oriental y el repentino cese de las actividades minero-metalúrgicas, acabe también la acuñación de todas estas pequeñas cecas, que pasa a concentrarse en Tui, Braga y Lugo. Este final de la acuñación de los pequeños centros se ha atribuido habitualmente al proceso de reorganización y centralización de la administración estatal por parte de Chindasvinto (642-649) y su sucesor Recesvinto (653-672), coincidiendo además con la devolución de las sedes meridionales de la Gallaecia sueva a la Lusitania ${ }^{107}$. Pero en realidad la última constatación de una amplia dispersión de cecas en el Noroeste ocurre durante el reinado de Suintila (621-631) (fig. 3); es decir no se produjo un corte súbito de las acuñaciones con la decisión política de Chindasvinto, como habría sido de esperar si las cecas no tuviesen relación con el comercio y la minería sino que parece un proceso que ya se había ido agotando algunos años antes, quizá entre el 635 y 642, en consonancia con la minería y comercio ${ }^{108}$. En todo caso, creemos que ambas explicaciones no son incompatibles, sino más bien distintos reflejos de un mismo proceso de rearticulación político-económica tras el fin de las bases y contextos que

105 R. Pliego, La moneda visigoda, pp. 227-228.

106 Es cierto que los hallazgos de monedas responden a la aleatoriedad, pero no deja de ser indicativo que, hasta el momento, todas las cecas conocidas respondan perfectamente a este patrón.

107 P.C. Díaz, Acuñación monetaria.

108 R. Pliego, La moneda visigoda, pp. 148-151. 
ligaban a las élites locales con la monarquía y la explotación de dichas minas. Por otro lado, es interesante señalar que en el resto de provincias de Hispania, no se produce esa desaparición brusca de cecas en torno al 640, sino que se mantienen, como parte de las dinámicas de negociación con poderes locales ${ }^{109}$.

No sabemos exactamente cómo se articularía la delegación de la explotación minera a través de la acuñación monetaria. En todo caso, parece claro que el rey establecía en un lugar determinado un taller con un delegado real, y acuñaba moneda para pagar a las élites de esa zona por sus servicios o fidelidad ${ }^{110}$. Esta moneda serviría para sellar u oficializar un pacto o delegación de la actividad extractiva a un poderoso local. Los reyes germánicos tratarían de promover subcontratas para evitar gasto administrativo, y estimularían a los propietarios privados a explotar recursos de oro, quizá también como respuesta a la obligación de pago fiscal ${ }^{111}$. Como señala $\mathrm{M}$. Hardt, la acumulación de tesoros, sobre todo en oro, era vital para los reyes y aristócratas de este período, para establecer lazos de fidelidad, mostrar su estatus y poder, etc. Por ello habría artesanos especializados en metales y tesoros, a la vez que el palacio real servía como distribuidor de riqueza entre sus clientelas y seguidores, para garantizar su fidelidad ${ }^{112}$. También es posible pensar que hubiese un pago habitual en lingotes de metal ${ }^{113}$. Como hipótesis, se puede pensar que esa moneda se emitía con la fundición de oro procedente de las minas y los impuestos pagados en esa zona, o bien de la compra de dicho metal con esos impuestos en las zonas en que no había oro. Quizá ese delegado podría explotar la restante cantidad de metal de las minas, una vez satisfecha la emisión de moneda. De todos modos, hay que insistir en que esta actividad minera no es la única explicación de las acuñaciones, ya que hay otras bases del poder económico y político articuladas a través de las cecas.

109 Hay que señalar que el hecho de que ya no se acuñe moneda en un lugar no significa que se acaben las relaciones con rey, ya que estas podían articularse de otras maneras (regalos, vinculos de fidelidad), pero en todo caso es indicativo de un giro con respecto a la situación precedente. M. Hardt, The accumulation of wealth

110 R. Pliego, La acuñación monetaria, p. 121, 129

111 J.C. Edmonson, Mining in the later Roman Empire, p. 98

112 M. Hardt, The accumulation of wealth

113 A. Harris, Byzantium, Britain and the West, pp. 70-72. 


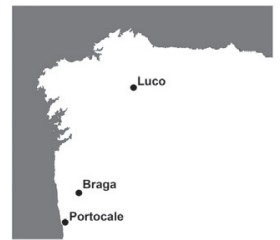

Leovigildo, 572-586

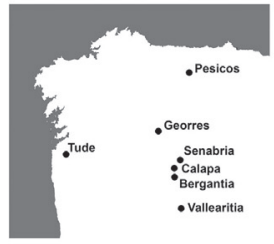

Gundemaro, 610-612

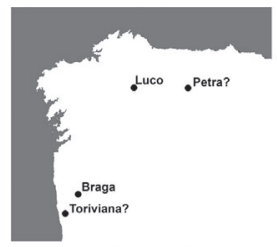

Chintila, 636-639

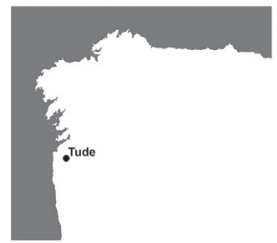

Wamba, 672-680

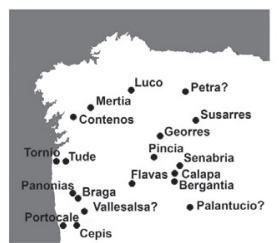

Recaredo, 586-601

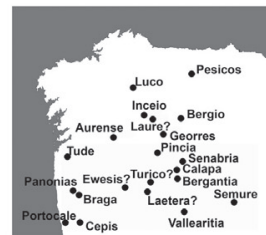

Sisebuto, 612-621

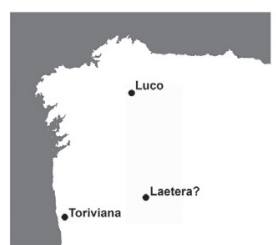

Tulga, 639-642

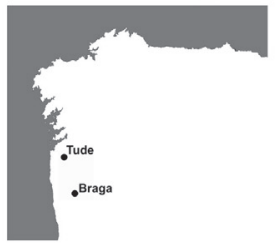

Égica, 687-695

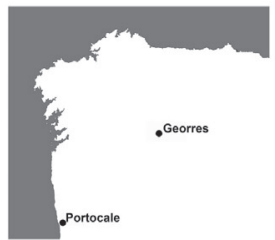

Liuva II, 601-603

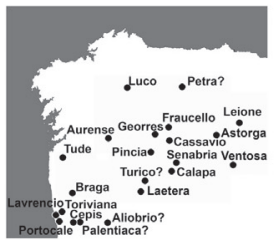

Suintila, 621-631

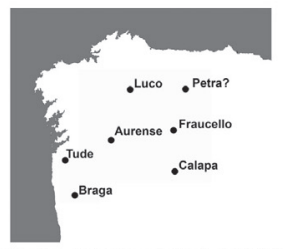

Chindasvinto (rey único), 642-649

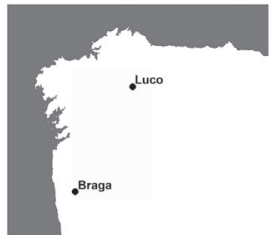

Egica y Witiza, 695-702

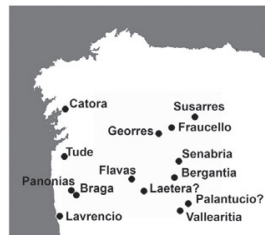

Witerico, 603-610

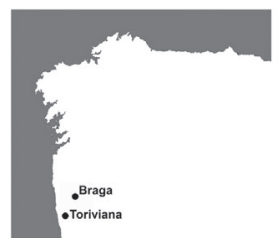

Sisenando, 631-636

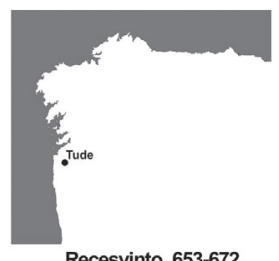

Recesvinto, 653-672

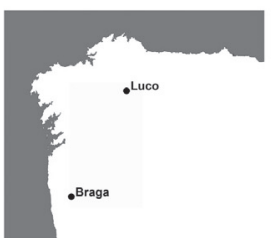

Witiza, 702-710

Fig. 3. Cecas con emisión de moneda constatada en cada reinado de la monarquía visigoda en el Noroeste de la Península Ibérica. Mapa elaborado a partir de la información de R. Pliego, La moneda, pp. 150-151.

En todo caso, además de estas delegaciones de las explotaciones reales, habría propietarios que explotaban los recursos mineros que existían en sus posesiones y pagaban los impuestos en metales, aunque también con el probable consentimiento del poder central ${ }^{114}$. Es de suponer que estas actividades no quedarían reflejadas en ninguna acuñación monetaria.

En ambos casos, como ya hemos señalado, estas minas no componían grandes explotaciones industriales, sino que se integrarían dentro de pro-

114 J.C. Edmonson, Mining in the later Roman Empire, p. 98. 
piedades más amplias de carácter agrícola, como un recurso más dentro de éstas ${ }^{115}$. Es difícil comprobar si esta producción minera tuvo relación con el uso de servi o esclavos que convivían con hombres libres, tal y como se ha propuesto en alguna ocasión, aunque parece una opción muy plausible ${ }^{116}$. Lo que sí es evidente es que solo los grandes propietarios tendrían los recursos para invertir capital en explotar mineral en sus propiedades o para subcontratar una concesión real, y solo ellos tendrían ya trabajadores de su propia mano de obra. Como señala J. C. Edmonson, se trata de un modo de producción bien adaptado a la coyuntura política y económica de este período, menos centralizada y más basada en pactos y vinculaciones entre los poderes centrales y locales $^{117}$.

\subsection{Los poderes económicos regionales: obispos, ecclesiae y el control de la producción}

Llegados a este punto, debemos ya plantear otra importante cuestión: ¿quiénes eran exactamente esos poderes regionales que explotaban las minas por delegación real o como parte de sus propiedades? Aunque no tenemos apenas datos, una serie de indicios nos hacen pensar que al menos una parte de este sistema económico estaba delegado o controlado por las jerarquías eclesiásticas de la Gallaecia tardoantigua, especialmente los obispos y su círculo inmediato.

El papel de las jerarquías eclesiásticas como motor económico en el Mediterráneo tardoantiguo parece cada vez más admitido por los investigadores $^{118}$. En un reciente trabajo, D. Bernal ha mostrado con evidencias arqueológicas cómo a menudo los obispos de distintas zonas del Mediterráneo estaban detrás, no solo de la elaboración de los productos exportados, sino también de la propia gestión del comercio entre los siglos IV-VII ${ }^{119}$. Parece probable que también en Gallaecia existiese un control episcopal del sistema productivocomercial de los siglos VI y VII que estamos analizando. El estudio de algunos textos de este período nos lleva en esta dirección.

En primer lugar, el análisis de la geografía eclesiástica del Reino suevo plasmada en el Parroquial suevo alrededor del año 570 d.C. Por supuesto,

115 Ibidem.

116 O. Puche, J. Bosch, Apuntes sobre la minería visigótica, p. 216.

117 J.C. Edmonson, Mining in the later, p. 99.

118 D. Bernal, Iglesia, producción; A. Harris, Byzantium, Britain and the West, pp. 74 y 138; A. Fernández, El comercio tardoantiguo, p. 739.

119 D. Bernal, Iglesia, producción. 
es necesario tener en cuenta las características y sentido de este texto, que refleja ante todo un proceso de organización en curso, y en el que solo se recogen las 'ecclesiae' (iglesias con función pastoral y de carácter diocesano) vinculadas a los obispados, y no otras fundaciones privadas ${ }^{120}$. En este listado ha llamado siempre la atención la desigual e irregular distribución de estas ecclesiae a lo largo de Gallaecia, que creemos que debe ponerse en relación con importantes diferencias en el grado de poder y control eclesiástico de cada obispado. En ese sentido, también es posible que algunas de estas peculiaridades en la organización eclesiástica galaica de finales del siglo VI respondan al mayor o menor control episcopal de ciertas áreas económicas de Gallaecia, y entre ellas, especialmente, las zonas mineras.

En el caso de la sede de Lugo, es interesante constatar que las tres únicas ecclesiae que el Parroquial recoge en dicha sede, se sitúan precisamente de la parte sur de la provincia, donde están los principales recursos auríferos de la misma: Carioca (Quiroga), Sevios (quizá Monforte de Lemos) y Cavarci (Cabarcos, en el municipio de Sobrado, en León). En el caso de la diócesis de Ourense, es evidente el predominio de ecclesiae en áreas mineras, al menos entre aquellas que se pueden localizar con cierta fiabilidad: Teporos (Trives), Geurros (Valdeorras), Cassavio (Casio), Pincia (Pinza), Calapacios (Calabor) $^{121}$. Algo similar ocurre en la sede de Astorga, en los casos de Bergido, Petra, Pesicos, y Fraucelos ${ }^{122}$.

En el caso de obispados más poderosos y dinámicos como Tude o Bracara, la distribución de las ecclesiae no está únicamente relacionada con zonas mineras, y es posible pensar en otras bases económicas importantes como la agricultura y la ganadería. Sin embargo, es interesante constatar como la sede de Tude parece expandir extrañamente sus límites "naturales" dentro del área orensana para contar con ecclesiae en ricas zonas de minería estannifera, como Aunone (Avión, Ourense), Carissiano (Carrizáns, A Lama, Pontevedra) o Sacria (Sagra, O Carballiño, Ourense) ${ }^{123}$. Algo similar ocurre con la mitad este de la extensa diócesis de Braga, la más alejada de la sede, cuyas ecclesiae se corresponden en todos los casos a enclaves mineros de primer orden como Bergantia (Braganza) o Flavas (Chaves) y quizá Turico, Ewesis o Laetera ${ }^{124}$.

En el caso de Iria Flavia, las ecclesiae de Pestomarcos, Mertia y Metacios se podrían poner en relación con la minería del estaño, mientras que otras como Salinae o Morratio, podrían vincularse al comercio maríti-

120 P.C. Díaz, El Parrochiale suevum.

121 J. C. Rivas, Antigüedad del episcopado.

122 R. Pliego, La moneda visigoda, pp. 137-142.

123 S. Vila, A diócese sueva, pp. 87-88.

124 J. Alarcao, As paróquias suévicas. 
mo. De hecho resulta difícil pensar que la base económica del obispado de Iria no tenga que ver con esta importancia del estaño en su entorno, y no es descabellado pensar que esta riqueza fuese una de las razones que explican la creación de una sede en este enclave, que reúne estratégicamente recursos mineros y una excelente salida al $\operatorname{mar}^{125}$. La primera noticia de la constitución de un episcopado en Iria Flavia (que sustituye al cercano de Aquis Celenis, Caldas de Reis) es del año 560, que es el momento en que este sistema productivo-comercial comienza su auge. También es posible que la extraña distribución de iglesias que la sede de Iria poseía "ex proprio" en torno al 868 fosilice parcialmente la importancia que había tenido la explotación del estaño más de dos siglos atrás ${ }^{126}$.

En cuanto a la peculiar sede de Britonia, sabemos que no hay recursos de oro y estaño en su área, aunque sí de hierro. En todo caso no sería descabellado pensar en algún papel de este obispado en las constatadas relaciones marítimas y comerciales de Gallaecia con la Galia y otras zonas del Atlántico.

Por tanto, la geografía eclesiástico-administrativa que podemos conocer principalmente a través del Parroquial Suevo podría tener parte de su lógica en el reparto, organización y control episcopal de áreas de actividades económicas, especialmente minero-metalúrgicas. Mientras que en esta geografía hay zonas y ejes que podemos considerar "centrales" (bien articulados en torno a las principales vías, a la costa, a los núcleos político-económicos, como el entorno de Braga, Lugo, Iria o Tui), hay otras áreas alejadas y periféricas (zona suroriental de Galicia, Bierzo, Tras-os-montes, A Estrada-Deza) que aparecen, sin embargo, muy vinculadas a las sedes episcopales. Todas ellas son potentes áreas mineras, mientras que, por el contrario, no se recogen en este documento ecclesiae en las otras muchas zonas "periféricas" no mineras.

Para entender adecuadamente este fenómeno, hay que tener en cuenta que los obispos representan en este momento un importante poder económico y patrimonial en la Hispania visigoda ${ }^{127}$. Pero, a la vez, es un poder que lucha fuertemente por su mantenimiento y crecimiento, a menudo a base de sobreexplotar y abusar de las ecclesiae que controlaba y de confundir su patrimonio personal con el que corresponde a su cargo eclesiástico ${ }^{128}$. Por otro lado, sabemos que en los momentos en los que se redacta el Parroquial y se desarrolla este sistema productivo-comercial, la jerarquía eclesiástica cuenta con el pleno

125 J. Suárez, En los orígenes, p. 167.

126 F. López Alsina, La ciudad, pp. 156-161.

127 C. Martin, Les évéques visigothiques; S. Castellanos, I. Martín Viso, The local articulation, p. 10

128 C. Buenacasa, Espiritualidad vs racionalidad. 
apoyo de la monarquía (en este caso sueva), de modo que la organización del Reino se identifica con la organización eclesiástica ${ }^{129}$, en un sistema del que ambas partes se benefician.

Es posible que, dentro de esta estrecha vinculación entre monarquía y obispos, como representantes de las aristocracias regionales, haya que enmarcar la delegación del control de una actividad de alto rendimiento económico en este contexto como es la minería. Así, por ejemplo, se puede entender que Tude, el obispado que controlaría el propio puerto de Vigo, sea una sede especialmente rica y poderosa, que muestra la mayor densidad de ecclesiae de todo el Reino suevo ${ }^{130}$ y que realiza acuñaciones monetarias de igual o mayor calidad que las de la propia sede real de Braga ${ }^{131}$. También se puede pensar que algunas de las estructuras eclesiásticas ligadas a posibles centros productivo-comerciales que hemos citado en apartados anteriores estuviesen en manos de los obispos, en ocasiones como ecclesiae del Parroquial suevo (como la ecclesia Marciliana, con restos romanos y altomedievales), y en otras como iglesias privadas del obispo, como gran propietario. Este último caso podría explicarse por los procesos de concentración de las propiedades, sobre todo de antiguas villae, en manos unos pocos pero muy poderosos grupos, que caracteriza a los siglos VI y VII ${ }^{132}$.

Enlazando con el apartado anterior, es posible que a menudo esta articulación entre la monarquía y las jerarquías eclesiásticas como delegadas de la explotación minera se produjese a través de las cecas. Este hecho queda reflejado en los abundantes casos en los que ecclesiae del Parroquial suevo coinciden con cecas pocos años después. En otros casos, sin embargo, hay cecas que no coinciden con ecclesiae conocidas en dicho texto. Quizá en algunos casos esto se debe a que dichas ecclesiae se crearon poco después de la redacción del Parroquial suevo, pero en otros podrían remitir a una articulación directa de un propietario privado con la monarquía.

Al margen del Parroquial suevo, otro indicio interesante de esta vinculación entre los grandes poderes eclesiásticos, las áreas de producción minera y la monarquía es la propia geografía de la vida y acción de San Fructuoso, en la primera mitad del siglo VII.

San Fructuoso pertenecía a una de las familias más poderosas de la Hispania visigoda del momento, que estaba estrechamente vinculada a la monarquía ${ }^{133}$. Es evidente que este patrimonio familiar está en la base de

\footnotetext{
129 P.C. Díaz, Acuñación monetaria.

130 J.C. Sánchez, Iglesias y dinámicas.

131 P. Bartlett, Dos monedas visigodas.

132 A. Chavarría, Villas en Hispania, pp. 33-34.

133 M.C. Díaz y Díaz, La Vida de San Fructuoso; S. Cantera, A. Rodríguez, Conciencia hispana y tradición.
} 
la importancia que alcanzará Fructuoso en la Iglesia visigoda, reflejada, entre otras cosas, en su nombramiento como obispo de Dumio y luego de Braga.

Pues bien, es muy indicativo que Fructuoso y su familia tengan su base patrimonial en la importante zona minera del Bierzo, y, sobre todo, que las fundaciones monásticas de Fructuoso (en terrenos, es de suponer, de su propiedad o relacionados con su control o redes familiares-clientelares) sigan claramente la geografía de todo este sistema económico. En el Bierzo funda los monasterios de Compludo y Rufianense, a los pies de minas de oro y en Folgoso de Courel, el de Visunia, al lado de una importante explotación aurífera (actual parroquia de San Fiz de Visuña) ${ }^{134}$. En la costa crea el monasterio Peonense, que podría ser el mismo que luego llama de Turonio, y probablemente otro monasterio en una isla. La mayoría de autores localizan estas dos fundaciones en las Rías Bajas, concretamente en el entorno de la Ría de Vigo y Pontevedra (monasterio de Poio o de Oia, y la isla de Ons o de Tambo), es decir, de nuevo en la principal salida al mar de las explotaciones metalíferas ${ }^{135}$. Por ello no es descabellado pensar que la distribución de las fundaciones monásticas de san Fructuoso en el Noroeste responda bien a estrategias económicas bien planificadas en el ámbito familiar, como sabemos que ocurrirá siglos después, por ejemplo, con las fundaciones de San Rosendo, y sobre todo, esté reflejando a través de ellas una actividad económica de su importante familia, ligada a la explotación de las minas del Bierzo y Courel, y su exportación marítima comercial en la Ría de Vigo. De hecho, no es casualidad que se cite explícitamente en su hagiografía la existencia de negotiatiores francorum comerciando en algún puerto del Noroeste, o se mencione el interés de San Fructuoso de embarcar hacia Oriente, es decir, Bizancio (previo paso por la Galia).

Otro posible indicio, con carácter más hipotético, es la Donación del rey Chindasvinto en el año 646 al monasterio de Compludo, recién creado por Fructuoso. Aunque existen muchas dudas sobre la autenticidad de este texto, algunos recientes análisis refuerzan la idea de que puede reflejar un hecho histórico verdadero ${ }^{136}$. Esta donación indicaría la relación de este noble y su familia con la monarquía, así como la propiedad o control real de muchos territorios en esta zona (ipsos montes et valles ab integro ${ }^{137}$ ). Dicho control real volverá a apreciarse en el texto de la "Autobiografía" de Valerio, cuando se señala cómo la hostilidad del rey cayó sobre la familia del rico propie-

134 M.C. Díaz y Díaz, La Vida de San Fructuoso, p. 89.

135 R. Puertas, Iglesias hispánicas, p. 71, M.C. Díaz y Díaz, La Vida de San Fructuoso, pp. 89-91.

136 M. Carriedo, Cuarenta obispos, p. 814.

137 Ibidem, doc. 28. 
tario Ricimer, que fue expulsada (probablemente por el rey Wamba, quizá por alguna infidelidad cometida contra el soberano), de la propiedad llamada "Ebronanto", situada también en el Bierzo ${ }^{138}$. Todo esto refleja claramente el control real sobre esta zona, aunque sea justamente en el momento en el que la actividad minera y el comercio están remitiendo. Podemos incluso pensar que precisamente por esto el rey busca ahora otras alianzas y estrategias con las aristocracias locales ya que no les puede ceder, como antes, los derechos sobre las minas.

No sabemos si los obispos explotaban directamente, a través de sus dependientes o siervos, este sistema económico y comerciaban también directamente, o si delegaban en propietarios locales. Por un lado, es indicativo el alto número de siervos que parece poseer la Iglesia visigoda, y concretamente la galaica ${ }^{139}$, hecho que le permitiría sin duda explotar directamente, al menos, las propiedades más inmediatas a su sede. Pero por otro lado, teniendo en cuenta la amplia dispersión de las evidencias de este sistema (minas, estructuras eclesiásticas, cecas...) y la conocida necesidad del obispo de "viajar" para negociar con las élites locales, parece posible pensar que otra parte de la producción estuviese, en efecto, delegada en propietarios locales. Por último, no hay que descartar la existencia de producciones autónomas de grandes propietarios, que vendiesen su mercancía a los centros eclesiásticos o directamente a los mercaderes orientales asentados en Vigo.

\section{CONCLUSIONES}

La combinación de datos y fuentes de muy distinto tipo, que habitualmente no suelen ponerse en relación, junto con los recientes avances en temas como el comercio, la moneda, el estudio del paleoambiente o la organización eclesiástica en la Gallaecia tardoantigua nos ha permitido constatar un interesante y prácticamente desconocido sistema económico supralocal de carácter productivo-comercial en el Noroeste peninsular durante algo más de un siglo, desde el primer tercio del siglo VI y mitad del siglo VII.

A pesar de los problemas y límites de la información disponible, que solo nuevos estudios arqueológicos podrán superar, creemos haber podido mostrar algunas de las características e implicaciones económicas y sociopolíticas de dicho sistema, a partir principalmente de uno de sus componentes mejor identificados: la minería.

138 R. Frighetto, Valério do Bierzo, pp. 103-106.

139 C. Buenacasa, Espiritualidad vs racionalidad; J. Carbajal, Los Concilios, p. 440. 
Frente a la tradicional negación, o minusvaloración, de las actividades mineras en este período, que se enmarca dentro de una concepción global de "debilidad" y oscuridad sobre éste, hemos constatado la existencia de una explotación relativamente importante, que obedece, sin embargo, a lógicas diferentes que la más grande y vistosa minería altoimperial romana. Esta actividad minero-metalúrgica, en pequeñas pero múltiples explotaciones de yacimientos primarios, parece estar íntimamente ligada a un intenso comercio a larga distancia con el imperio bizantino, ya que su coincidencia cronológica es casi absoluta, formando todo un mismo sistema económico-productivo. Este sistema nos informa de un elevado nivel de contactos e influencias externas en la Gallaecia de este período, frente a habituales concepciones de periferia y aislamiento. No obstante, hay que subrayar las importantes diferencias económicas según zonas de Gallaecia que impiden cualquier generalización simplista de estas dinámicas y obligan siempre a un conocimiento del contexto local.

En todo caso, este trabajo constituye tan solo un primer paso para valorar y encuadrar históricamente este sistema económico. Será necesario en el futuro continuar afinando la posible conexión entre estas actividades productivo-comerciales y las numerosas evidencias histórico-arqueológicas que parecen existir a su alrededor: estructuras eclesiásticas, conexión con vías de comunicación (marítimas, terrestres y fluviales), existencia de una posible red de fortificaciones que controlaba la producción o circulación, etc., además de explorar otras actividades productivas que pudieron existir dentro de este sistema, como las elaboración de pieles y curtidos o la explotación de madera.

En segundo lugar, queremos subrayar el potencial de las conclusiones que se pueden extraer para el conocimiento de las estructuras socio-económicas de las élites tardoantiguas del Noroeste peninsular. A diferencia del sistema productivo-comercial romano, caracterizado por una diversidad de focos y protagonistas que en la costa gallega parece acabar, como muy tarde, en torno a mitad del siglo VI, el sistema que aquí hemos estudiado se presenta como un fenómeno más intenso, pero a la vez más focalizado y aparentemente más restringido, prestigioso y elitista. Esto nos hace pensar que deben ser las élites más importantes y de carácter supralocal las que controlaban dicho sistema: obispos y otros grandes propietarios señoriales, estrechamente vinculados a la monarquía, que en última instancia era la propietaria de muchas de las zonas fiscales donde se producían los recursos exportados, sobre todo metales. Esto nos da idea del alcance del control territorial en este período, a menudo considerado oscuro y de debilidad.

Sin embargo, la monarquía precisaría de la colaboración de las élites locales o regionales, y por eso delegaba en ellas la explotación de los recursos metalíferos a través de pactos fiscales; pactos que a menudo se reflejan en la 
acuñación de moneda. Como señalan S. Castellanos e I. Martín Viso, las esferas locales y centrales en este período no son simples competidoras ni antagonistas, sino que el poder en este período se basa en la búsqueda de formas de colaboración, aunque no siempre se lograsen ${ }^{140}$. En el caso del Noroeste esto se plasma en una interesante geografía del poder político-económico, de la cual nos quedan destellos en aspectos tan variopintos como la distribución de las cecas, las fundaciones fructuosianas en la primera mitad del siglo VII o las áreas de control episcopal que en última instancia representa el Parroquial suevo hacia finales del siglo VI. En este sentido hay que subrayar sobre todo la importancia de la figura de los obispos en el ámbito regional, como enlaces o bisagras con la monarquía. Sin embargo, no se trata de un poder monolítico, sino que detrás de sus figuras hay luchas, estrategias, apropiaciones y diferentes bases económicas.

Desde una perspectiva histórica más amplia lo que tenemos ante nosotros, en definitiva, es un contexto de fortalecimiento de los poderes supralocales, y sus contactos externos, del Noroeste entre inicios del siglo VI (tras una época previa de inestabilidad y mayor desarticulación del Reino suevo ${ }^{141}$ ) y mitad del siglo VII. En este período Gallaecia vive una cierta etapa de auge y dinamismo político y económico, y sin duda este sistema económico debe estar detrás, al menos en parte, de esta vitalidad. Como ha señalado C. Wickham, existe una estrecha vinculación entre el poder de las élites y su capacidad para impulsar un comercio externo ${ }^{142}$. En ese sentido, es posible pensar que hasta que Bizancio no encontró en Gallaecia unas élites estructuradas y una adecuada organización productiva, a inicios del segundo tercio del siglo VI, no la convirtió en su nueva aliada político-económica y proveedora de metales en sustitución del más lejano, y por tanto costoso, Suroeste británico. Se trata de un contexto que no acaba con la conquista visigoda del Reino suevo, sino que continúa al menos 60 años más ${ }^{143}$. De hecho es posible que una de las razones de esta conquista esté ligada a la importancia de este sistema económico, que la monarquía visigoda trataría de controlar.

Sin embargo, a partir de mitad del siglo VII las evidencias de desarticulación y de mayor presión de los poderes locales aumentan. Aunque durante la segunda mitad del siglo VII pudo pervivir un cierto comercio atlántico, éste se perderá definitivamente en el VIII, con la invasión árabe, y el nacimiento del comercio de la Europa del Norte, que deja, ahora sí, a esta zona en una posición más periférica y aislada hasta su progresiva incorporación al Reino astur-leonés a inicios del siglo IX.

140 S. Castellanos, I. Martín Viso, The local articulation, p. 16.

141 P.C. Díaz, El Reino Suevo, pp. 191-206.

142 C. Wickham, Rethinking the structure.

143 P.C. Díaz, Acuñación monetaria, p. 375. 


\section{BIBLIOGRAFÍA CITADA}

Alarcao, Jorge de, As paróquias suévicas do território actualmente português, en Villar, F.; Fernández, M.P. (eds). Religión, lengua y cultura prerromanas de Hispania, Salamanca, Universidad de Salamanca, 2001, pp. 29-60.

Álvarez-Campana Gallo, José Manuel, Contribución das minas de San Finx (Lousame) á historia mineira do Barbanza, en López Otero, M. L.; Álvarez-Campana Gallo, J.M. (coord.), Introducción á minería no Barbanza, Boiro, Cámara Oficial Mineira 2008, pp. 29-39.

Ayán, Xurxo; Moledo, Xosé; González, Leonardo; González, Eduardo, Etnoarqueoloxía e paleometalurxia de Os Castros de Neixón (Boiro, A Coruña), en López Otero, M.L.; Álvarez-Campana Gallo, J.M. (coord.), Introducción á minería no Barbanza, Boiro, Cámara Oficial Mineira 2008, pp.83-120.

Barbero, Abilio; Vigil, Marcelo, La formación del feudalismo en la Península Ibérica, Barcelona, Crítica, 1978.

Bartlett, Peter, Dos monedas visigodas de Tude recientemente adquiridas por el Museo de Pontevedra, "El Museo de Pontevedra" 59 (2005), pp. 313-318.

Bernal-Casasola, Darío, Iglesia, producción y comercio en el Mediterráneo tardoantiguo. De las ánforas a los talleres eclesiásticos, en LRCW3: Late Roman coarse wares, cooking wares and amphorae in the Mediterranean Oxford, BAR, 2010, pp. 19-31.

Bonilla Rodríguez, Andrés, Trabajos arqueológicos en el Monasterio e Iglesia de S. Lorenzo de Carboeiro (Silleda, Pontevedra), "Brigantium" 12, (2000), pp.253-255.

Brañas, Rosa, Cruz de Moraime, Muxía, A Coruña, en Singul, F.; Suárez, J. (eds.), Até o confín do mundo: diálogos entre Santiago e o mar, Vigo, Museo do Mar de Galicia, 2004, p. 79.

Brogiolo, Gian Pietro; Chavarría, Alexandra, Aristocrazie e campagne nell'Occidente da Costantino a Carlo Magno, Florencia, All'Insenga del Giglio, 2005.

Buenacasa Pérez, Carles, Espiritualidad vs racionalidad económica: los dependientes eclesiásticos y el perjuicio económico a la iglesia de Dumio en el Testamento de Ricimiro (656), "Polis" 16 (2004), pp. 7-32.

Cabeza Quiles, Fernando, Toponimia de Galicia, Santiago, Galaxia, 2008.

Campbell, Ewan, Continental and Mediterranean imports to Atlantic Britain and Ireland, AD 400-800, York, CBA, 2007.

Cantera Montenegro, Santiago, Rodríguez De La Peña, Manuel, Conciencia hispana y tradición monástica en la Vita Fructuosi, "Cuadernos de Estudios Gallegos" 54/120 (2007), pp. 71-102. 
Carbajal Sobral, José, Los Concilios de Braga en los siglos VI y VII como reflejo de la vida en la Gallaecia de la época, Vigo, Imprenta Paz, 1999.

Carriedo Tejedo, Manuel, Cuarenta Obispos de Galicia, de 561 a 711 (anteriores a la invasión musulmana), "Estudios mindonienses" 20 (2004), pp. 773-847.

Carro Otero, José, Tres esqueletos de la necrópolis galaico-visigótica de San Xoao de Moraime (Muxía- La Coruña), "Cuadernos de Estudios Gallegos" 36/101 (1988), pp. 7-53.

Castellanos, Santiago, Ofensivas aristocráticas y articulación política en el norte hispano post-romano, en Espinosa, U.; Castellanos, S. (eds.), Comunidades locales y dinámicas de poder en el norte de la Península Ibérica durante la Antigüedad Tardía, Logroño, Universidad de La Rioja, 2006, pp. 141-164.

Castellanos, Santiago; Martín Viso, Iñaki, The local articulation of central power in the north of the Iberian Peninsula, "Early Medieval Europe" 13 (2005), pp. 1-42.

Chamoso Lamas, Manuel, Sobre las necrópolis paleocristianas ultimamente descubiertas en Galicia y Portugal, "Anuario de Estudios Medievales" 2 (1965), pp. 433-450.

Chamoso Lamas, Manuel, Excavaciones arqueológicas en San Julian de Moraime (Mugía, La Coruña), "Noticiario Arqueológico Hispánico" 4 (1976), pp. 335-350.

Chavarría Arnau, Alexandra, Villas en Hispania durante la Antigüedad tardía, en Chavarría, A.; Arce, J.; Brogiolo, G. P. (eds), Villas tardoantiguas en el Mediterraneo Occidental, Madrid, CSIC, 2006, pp. 17-35.

Cunliffe, Barry, Facing the Ocean. The Atlantic and its peoples, Oxford, Oxford University Press, 2001.

Díaz Martínez, Pablo de la Cruz, El Parrochiale suevum: organización eclesiástica, poder político y poblamiento en la Gallaecia tardoantigua, en Mangas, J.; Alvar, J. (eds.), Homenaje a José María Blázquez, Madrid, Ediciones Clásicas, 1998, pp. 35-47.

Díaz Martínez, Pablo de la Cruz, Acuñación monetaria y organización administrativa en la Gallaecia tardoantigua, "Zephyrus" 57 (2004), pp. 367-375.

Díaz Martínez, Pablo de la Cruz, Extremis mundi partibus. Gallaecia tardoantigua: periferia geográfica e integración política, en Espinosa, U.; Castellanos, S. (eds.), Comunidades locales y dinámicas de poder en el norte de la Península Ibérica durante la Antigüedad Tardía, Logroño, Universidad de La Rioja, 2006, pp. 201-215.

Díaz Martínez, Pablo de la Cruz, El Reino Suevo, Madrid, Akal, 2011. 
Díaz y Díaz, Manuel Cecilio, La Vida de San Fructuoso de Braga. Estudio y Edición Crítica, Braga, Diario do Minho, 1974

Díaz y Díaz, Manuel Cecilio, La cristianización en Galicia, en Acuña, F. (ed.), La romanización de Galicia, Sada, Ediciós do Castro, 1992, pp. 105-120.

Díaz y Díaz, Manuel Cecilio, La Diócesis de Iria-Compostela hasta 1100, en García Oro, J. (coord.), Iglesias de Santiago de Compostela y TuyVigo, Madrid, Biblioteca de Autores Cristianos, 2002, pp. 9-40.

Edmonson, Jonathan Charles, Mining in the later Roman Empire and beyond: continuity or disruption? "Journal of Roman Studies" 79 (1989), pp. 84-102.

Feijoo Martínez, S.; Rúa Carril, V., La iglesia prerrománica de San Martín de Prado en Lalín Pontevedra-España, "Informes de la Construcción" 46/435 (1995), pp. 91-100.

Fernández Fernández, Adolfo, Resultados preliminares del estudio de la T.S. Focense (LRC) aparecida en Vigo (Galiza, España), en Rei Cretariae Romanae Fautorum. Acta 41, Bonn, Rei Cretariæ Romanæ Fautores, 2010, pp. 375-384.

Fernández Fernández, Adolfo, As relacións externas da Gallaecia durante os séculos IV-VII d.C. a traverso do material importado localizado en Vigo (Galiza), en Hidacio da Limia e o seu tempo, Xinzo de Limia, Concello de Xinzo, 2011, pp. 1-43.

Fernández Fernández, Adolfo, El comercio tardoantiguo (ss. IV-VII) en el Noroeste peninsular a través del registro arqueológico de la Ría de Vigo, Orense, Universidade de Vigo, 2011 (tesis doctoral inédita).

Fernández Martínez, F., Minería de Galicia, en Xeografía de Galicia. Volumen 5: Xeografía Económica (I), Santiago [s.n.] 1995, pp. 263-294.

Fernández Ochoa, Carmen; Gil Sendino, Fernando; Villar Calvo, Almudena; Fernández Rodríguez, Natalia; Álvarez Toledo, Gonzalo; Morán Fernández, Orlando, La villa romana de Veranes (Gijón, Asturias). Aportaciones preliminares sobre la transformación funcional del asentamiento en la tardía antigüedad, "Cuadernos de prehistoria y Arqueología de la Universidad Autónoma de Madrid" 31-32 (2005-2006), pp. 137-194.

Francovich, Riccardo, Per una storia sociale delle attività estrattive e metallurgiche: a proposito di alcune recenti ricerche archeologiche nella Toscana mineraria del Medioevo, en Actas de las I Jornadas sobre minería y tecnología en la Edad Media peninsular, León, Fundación Hullera Vasco-Leonesa, 1996, pp. 19-35.

Freire Camaniel, José, ¿Un testimonio epigráfico de la existencia, en Orense, de un Duque de Leovigildo?, "Boletín Auriense" 18-19 (1989), pp. 133-141.

ANUARIO De ESTUdios Medievales, 44/2, julio-diciembre 2014, pp. 983-1023 ISSN 0066-5061, doi:10.3989/aem.2014.44.2.10 
Frighetto, R., Valério do Bierzo. Autobiografia, Noia, Toxosoutos, 2006.

García Moreno, Luis, Las relaciones internacionales del Reino Godo de Toledo en el siglo VII: de la faida gótica a la obsesión bizantina, en Le relazioni internazionali nell'Alto Medioevo. Spoleto, Fondazione Centro italiano di studi sull'alto Medioevo, 2011, pp. 481-559. (Atti delle Settimane di Studio del Centro Italiano di Studi sull'Alto Medioevo; 58)

Garrido Rodríguez, Jaime, Fortalezas de la antigua provincia de Tuy, Pontevedra, Diputación de Pontevedra, 1987.

González Fernández, Alberto, Intervención arqueológica en A Illa do Medio. Santa Comba (Cobas), en Santa Comba. Un referente arqueológico en la costa ferrolana, Ferrol, Sociedade Cultural Columbia, 2002, pp. 67-157.

Gurriarán, Ricardo, Da prerromanización ao wolfram: apuntamentos históricos das explotacións mineiras en Valdeorras, Santiago de Compostela, Tórculo, 2000.

Gutiérrez González, José Avelino; Argüello Menéndez, José; Larrazábal Galarza, Javier, Minería y metalurgia en torno a la Cordillera Cantábrica. Primeras evidencias arqueológicas y propuestas de estudio, en Actas del IV Congreso de Arqueología Medieval española, Alicante, Asociación Española de Arqueología Medieval, 1994, pp. 905-917.

Hardt, Matthias, The accumulation of wealth in early medieval aristocracies, en Archeologia e società tra Tardo Antico e Alto Medioevo, Mantova, SAP, 2007, pp. 253-256.

Harris, Anthea, Byzantium, Britain and the West. The archaeology of cultural identity, Stroud, Tempus, 2003.

Lamas Bértolo, Jorge, Actuación arqueolóxica preventiva do proxecto do centro lúdico spa Parador de Turismo de Santo Estevo, en Actuacións arqueolóxicas. Ano 2006, Santiago, Xunta de Galicia, 2008, pp. 87-88.

Lebecq, Stéphane, The role of the monasteries in the systems of production and exchange of the Frankish world between the seventh and the begining of the ninth centuries, en Hansen, L.; Wikcham, C. (eds.), The Long Eighth Century. Production, Distribution and Demand, Leiden, Brill, 2000, pp. 121-148.

López Alsina, Fernando, La ciudad de Santiago en la Alta Edad Media, Santiago, Ayuntamiento de Santiago, 1988.

López Quiroga, Jorge; Rodríguez Lovelle, Mónica, Cecas y hallazgos monetarios de época suevo-visigoda, en II Encuentro Peninsular de Numismática Antigua (1997, Porto), Madrid, CSIC, 1999, pp. 433-439.

Lorenzo Fernández, J., La iglesia prerrománica de Santa María de Mixós, "Boletín Auriense" 2 (1972), pp. 75-110.

ANUARIO De ESTUdios Medievales, 44/2, julio-diciembre 2014, pp. 983-1023

ISSN 0066-5061, doi:10.3989/aem.2014.44.2.10 
Martí, Ramón, Los faros en al-Andalus: un sistema original de transmisión de señales, en Fars de l'islam, antigues alimares d'al-Andalus, Barcelona, EDAR, 2008, pp. 189-218.

Martin, Céline, Les évéques visigothiques dans leur espace: de l'autonomie à l'intégration, en Les élites et leurs espaces. Mobilité, rayonnement, domination (du VIe au XIe siècle), Turnhout, Brepols, 2007, pp. 207-223.

Martínez Cortizas, Antonio; Mighall, Tim; Pontevedra Pombal, Xavier, Nóvoa Muñoz, J. C.; Peiteado Varela, E.; Rebolo Piñeiro, R., Linking changes in atmospheric dust deposition, vegetation change and human activities in northwest Spain during the last 5300 years, "The Holocene" 15/5 (2005), pp. 698-706.

Martínez Cortizas, Antonio; Novoa Muñoz, J. C.; Pontevedra Pombal, Xavier; García-Rodeja, E.; Llana Rodríguez, C., Paleocontaminación. Evidencias de contaminación atmosférica antrópica en Galicia durante los últimos 4000 años, "Gallaecia" 16 (1997), pp. 7-22

Menéndez Bueyes, José Ramón, Reflexiones críticas sobre el orígen del Reino de Asturias, Salamanca, Universidad de Salamanca, 2001.

Moreno, Laura; Gallego, J.L.R.; Ortiz, J.E.; Torres, T.; Sierra, C., Distribución de elementos traza en el registro de la Turbera de Roñanzas (Asturias, España), "Geogaceta" 46 (2009), pp. 123-126.

Naveiro López, Juan, El comercio antiguo en el N.W. peninsular, La Coruña, Museo Arqueolóxico de A Coruña, 1991.

Novo Guisán, José Miguel, Lugo en los tiempos oscuros. Las menciones literarias de la ciudad en los siglos Vy X, "Boletín do Museo Provincial de Lugo" 10 (2001-2002), pp. 251-258.

Núñez Rodríguez, Manuel, Arquitectura prerrománica, Santiago, COAG, 1978.

Orlowski, Sabrina, Fideles Regis en el Reino Visigodo de Toledo: aproximaciones para su estudio desde las prácticas identitarias, "Miscelánea Medieval Murciana" 34 (2010), pp. 83-91.

Pérez Losada, Fermín, Os asentamentos na Galicia romana, en Historia de Galicia I, La Coruña, Hércules Ediciones, 1991, pp. 403-442.

Pliego Vázquez, Ruth, La acuñación monetaria en el Reino Visigodo de Toledo: El funcionamiento de las cecas, en Els tallers monetaris: organització i producció, Barcelona, MNCARS, 2008, pp. 117-141.

Pliego Vázquez, Ruth, La moneda visigoda, Sevilla, Universidad de Sevilla, 2009.

Puche Riart, Octavio, Bosch Aparicio, Juan, Apuntes sobre la minería visigótica hispana, en Actas de las I Jornadas sobre minería y tecnología en la Edad Media peninsular, León, Fundación Hullera Vasco-Leonesa, 1996, pp. 198-216. 
Puertas Tricas, Rafael, Iglesias hispánicas (siglos IV al VIII). Testimonios literarios, Madrid, Dirección General de Patrimonio Artístico, 1975.

Quirós Castillo, Juán Antonio, Early medieval landscapes in north-west Spain: local powers and communities, fifth-tenth centuries, "Early Medieval Europe" 19/3 (2011), pp. 285-311.

Ramil González, Emilio, Historia de Cariño da prehistoria á etapa altomedieval, Cariño, Concello de Cariño, 1999.

Rivas Fernández, Juan Carlos, Antigüedad del episcopado auriense, Orense, Duen de Bux, 2003.

Rivas, Eligio; Delgado, Jaime, Un bajorrelieve visigótico en Asadur con la escena del Calvario, "Porta da Aira. Revista de historia del arte orensano" 4 (1991), pp. 9-22.

Rodríguez Colmenero, Antonio, Historia del arte romano de Galicia, en Galicia en Arte prehistórico y romano, La Coruña, Hércules Ediciones, 1993, pp. 237-540.

Rodríguez Colmenero, Antonio; Ferrer Sierra, Santiago; García Tato, Isidro, Priorato de Xagoaza (Valdeorras, Ourense), Orense, Fundación Aquae Querquennae, 2009.

Rodríguez Resino, Álvaro, Do imperio romano á Alta Idade Media. Arqueoloxía da Tardoantigüidade en Galicia (séculos V-VIII), Noia, Toxosoutos, 2005.

Salter, Christopher, Early tin extraction in the south-west of England: a resource for Mediterranean metalworkers of late antiquity? en Mundell, M. (ed.), Byzantine trade, 4th-12th centuries, Farnham, Ashgate, 2009, pp. 315-321.

Sánchez Pardo, José Carlos, Iglesias y dinámicas sociopolíticas en el paisaje gallego de los siglos V-VIII, "Hispania" (en prensa).

Sánchez Pardo, José Carlos, Arqueología de las iglesias tardoantiguas en $\mathrm{Ga}$ licia (ss. V-VIII). Una valoración de conjunto, "Hortus Artium Medievalium" 18/2 (2012), pp. 395-414.

Suárez Otero, José, Sobre las laudas de doble estola en Santiago de Compostela e Iria Flavia, "Abrente" 29 (1997), pp. 41-47.

Suárez Otero, José, En los orígenes... en Vázquez Portomeñe, A. (coord.), Peregrinación y caminos, La gran obra de Los Caminos de Santiago. Iter Stellarum, vol. I, La Coruña, Hércules ediciones, 2004, pp. 152-199.

Suárez Otero, José, Crismón de San Pedro de Leis, en Singul, F.; Suárez, J. (eds.), Até o confín do mundo: diálogos entre Santiago e o mar, Vigo, Museo do Mar, 2004, p. 91.

Vidal Álvarez, S., Frontal de sarcófago. Igrexa de San Sadurniño de Goiáns, Portosín, Porto de Son, A Coruña, en Singul, F.; Suárez, J. (eds.), Até 
o confín do mundo: diálogos entre Santiago e o mar, Vigo, Museo do Mar de Galicia, pp. 82-83.

Vila Botanes, Suso, A diócese sueva de Tui, "Boletín de estudios del Seminario Fontán-Sarmiento" 21 (2000), pp. 85-89.

Wickham, Chris, Framing the Early Middle Ages. Europe and the Mediterranean, 400-800, Oxford, Oxford University Press, 2005.

Wickham, Chris, Rethinking the Structure of the Early Medieval Economy, en Davis, R.; McCormick, M., The long morning of medieval Europe: new directions in Early Medieval studies, Aldershot, Ashgate, 2008, pp. 19-31.

Yzquierdo Perrín, Ramón, Arte Medieval (I), La Coruña, Hércules ediciones, 1993.

Fecha de recepción del artículo: abril 2012

Fecha de aceptación y versión final: enero 2013 